\title{
¿La Corte Suprema de Justicia argentina se reinventa, presentándose como un tribunal constitucional?
}

\author{
Víctor Bazán \\ vicba2002ar@yahoo.com.br \\ Profesor Titular Efectivo de \\ Derecho Constitucional y \\ Derecho Internacional Público de la \\ Facultad de Derecho Y Ciencias Sociales \\ de la Universidad Católica de Cuyo, \\ San Juan, Argentina. \\ Recebimento do artigo: 29/01/2010 \\ Aprovado em: 12/08/2010
}

\section{Resumen}

En el presente trabajo el autor enfoca el proceso en el que se encuentra inmersa la Corte Suprema de Justicia argentina, fundamentalmente a partir de su nueva composición, para diseñar una nueva identidad institucional y perfilar un remozado esquema de jurisdicción constitucional. Las claves del análisis se concentranenel escenario jurídico argentino a partir de la reforma constitucional de 1994; las exigencias del Estado Constitucional de Derecho, estrechamente ligado al neoconstitucionalismo; el rol del juez en dicho modelo; la complejización de la tarea jurisdiccional; y las líneas de recorrido que recientemente el Tribunal viene trazando en distintos aspectos significativos del control de constitucionalidad y al fijar ciertas posiciones institucionales firmes en sus sentencias y acuerdos. La

respuesta al interrogante lanzado desde el título del ensayo vendrá de la mano del examen de la conjunción de ingredientes y condimentos que tipifican la actualidad y la prospectiva jurídico-constitucional argentina; la creciente importancia de la interacción del derecho constitucional, el procesal constitucional y el internacional de los derechos humanos; y los desafíos jurídicos y políticos que afronta la Corte Suprema en busca de la relocalización de su emplazamiento en el sistema institucional argentino.

\section{Palavras Clave}

Derecho Procesal Constitucional. Derecho Constitucional. Jurisdicción constitucional. Sentencias constitucionales. Corte Suprema de Justicia Argentina. 


\title{
Should the argentine supreme court of justice reinvent and present itself as a constitutional court?
}

\author{
Víctor Bazán
}

\section{Abstract}

The Supreme Court of Argentina, particularly with its new membership, is undergoing a process aimed at creating a different institutional identity and at tailoring a renewed scheme of constitutional jurisdiction. The key elements of the analysis of this process are focused on the Argentine legal framework subsequent to the 1994 constitutional reform; the constitutional state de iure, strictly binded to neoconstitucionalism; the role that a judge plays in such a model; the more complex jurisdictional function; and some recent cases of this Court that decided meaningful aspects of constitutional review or where it took certain firm institutional stances. The author answers the question asked in this essay title analyzing the mix of elements and influences that typify the current and future Argentine constitutional and legal situation; the greater interaction between constitutional law, constitutional procedural law and international human rights law; and the legal and political challenges that the Supreme Court faces in the pursue of a relocation in the Argentine institutional system.

\section{Key Words}

Constitutional Procedural Law. Constitutional Law. Constitutional Jurisdiction. Argentine Supreme Court of Justice. 


\section{Sumario}

I Consideraciones introductorias y plan del trabajo.

II Apreciaciones contextuales para comprender algunas facetas del escenario jurídico-político actual en Argentina.

1 Impronta de la reforma constitucional de 1994.

2 En torno al neoconstitucionalismo(s).

3 Otros rasgos que tipifican el escenario jurídico argentino.

4 El rol de la magistratura judicial.

5 La Corte Suprema, los cambios en su composición y algunos intentos por "marcar su territorio".

III El proceso de rediseño de su identidad institucional

1 Liminar.

2 Jurisprudencia relativa a decisiones de fondo y a otros pronunciamientos en el marco de la configuración de la competencia originaria de la Corte.

3 Algunos importantes acuerdos del Tribunal.

IV Un intento por decodificar y relacionar determinados mensajes y señales que emite el Tribunal

1 Insumos conceptuales.

2 Nuestra lectura decodificatoria de la cuestión.

V De ciertos desafíos y temas pendientes que la Corte Suprema tiene por delante.

VI Apreciaciones finales y de conjunto. 


\section{Consideraciones introductorias y plan del trabajo}

Para absolver el interrogante lanzado en el rótulo de este trabajo, cuya respuesta afirmativa llevaría a imaginar una metamorfosis del Tribunal, comenzaremos presentando diversos ingredientes de peso que tipifican el escenario jurídico en el que debe moverse la Corte Suprema de Justicia de la Nación (en adelante, la Corte o la Corte Suprema) e interactuar con los otros poderes y órganos del Estado, con los operadores del derecho y con el pueblo como consumidor jurídico.

Así, relevaremos sucesivamente la impronta que en algunos temas trascendentes imprimió - al menos desde el plano normativo - la innovación constitucional de 1994; las señales que transmite/n el/los "neoconstitucionalismo/s"; la disonancia que se genera entre el proceso de "constitucionalización" que de una lectura exclusivamente normológica de aquella reforma constitucional pareciera que ésta profundizó en el sistema jurídico argentino, y la suerte de contrafenómeno de "desvirtuación o distorsión constitucionales" que se vivencia en el plano fáctico; el rol de la magistratura judicial en el Estado Constitucional de Derecho y el crecimiento incesante de demanda de justicia por parte del pueblo, ámbito donde aflora la paradoja que puede sintetizarse afirmando que a mayor desconfianza y percepción de devaluación del Poder Judicial, mayor (cuantitativa y cualitativamente) requerimiento de justicia se le dirige; y, finalmente, los cambios en la composición de la Corte Suprema argentina y algunas "urgencias" que ello trajo consigo.

Delineada la multifacética fisonomía del paisaje jurídico-político en el que debe operar el Máximo Tribunal y las nutridas exigencias que la hora actual le impone, recorreremos las líneas jurisprudenciales que viene trazando recientemente en distintos aspectos significativos del control de constitucionalidad y al trasuntar en otras cuestiones una firme posición institucional como cabeza de uno de los poderes del Estado; actitud que no se agota en los fallos judiciales sino que también se hace perceptible en ciertos importantes acuerdos que ha emitido.

Seguidamente, procuraremos decodificar algunos signos que emanan de tal conjunto de pronunciamientos y acordadas para verificar si es jurídicamente sustentable pronosticar que la reconfiguración de su silueta institucional es lo suficientemente potente para convertirla en un tribunal constitucional, al menos desde un ángulo material.

A continuación, enunciaremos - sin intención alguna de exhaustividad - determinadas cuestiones pendientes que se erigen en desafíos para el Tribunal, ya vinculados a temas conflictivos que deberá definir a través del examen de constitucionalidad en un futuro no muy lejano, ya conectados con otras facetas, también relevantes, que hacen a su más adecuado funcionamiento como máximo órgano jurisdiccional nacional. 
A su tiempo, el epílogo vendrá de la mano de las apreciaciones recapitulativas que se añadirán a las consideraciones conclusivas intercaladas en el nudo del trabajo.

\section{Apreciaciones contextuales para comprender algunas facetas del escenario jurídico-político actual en Argentina}

\section{Impronta de la reforma constitucional de 1994}

Entre otros aspectos importantes de los que se ha ocupado la innovación constitucional de 1994, y sin propósito de taxatividad, pueden contabilizarse los siguientes elementos que deben ser tomados en consideración: la entronización de un postulado trascendente de autoafirmación de su fuerza normativa (art. 36); la ampliación del plafón de derechos explícitos (v. gr., arts. 37, 41, 42); la literalización de los procesos constitucionales de amparo, hábeas corpus y hábeas data ${ }^{1}$ (art. 43); el diseño de un nuevo paradigma del principio de igualdad, caracterizado por la exigencia de complementación de la igualdad formal (art. 16) con la igualdad material (arts. 37 y 75, incs. 19 y 23); y la adjudicación de jerarquía constitucional a once instrumentos internacionales en materia de derechos humanos (art. 75, inc. 22, párr. $2^{\circ 2}$ ) y a los que en el futuro se les acuerde tal valencia (párr. $3^{\circ}$ de dicho inciso ${ }^{3}$ ),

Aunque, en este último caso, sin literalizar la denominación "hábeas data".

2 La atribución de jerarquía constitucional se hizo en las condiciones de vigencia de los instrumentos internacionales citados en dicho párr. $2^{\circ}$ del inciso analizado, además de consignar que aquéllos no derogan artículo alguno de la primera parte de la Constitución (es decir, la fracción dogmática) y que deben entenderse complementarios de los derechos y garantías por ella reconocidos. Los documentos internacionales recipiendarios de jerarquía constitucional originaria son: la Declaración Americana de los Derechos y Deberes del Hombre; la Declaración Universal de Derechos Humanos; la Convención Americana sobre Derechos Humanos; el Pacto Internacional de Derechos Económicos, Sociales y Culturales; el Pacto Internacional de Derechos Civiles y Políticos y su Protocolo Facultativo; la Convención sobre la Prevención y la Sanción del Delito de Genocidio; la Convención Internacional sobre la Eliminación de todas las Formas de Discriminación Racial; la Convención sobre la Eliminación de todas las Formas de Discriminación contra la Mujer; la Convención contra la Tortura y otros Tratos o Penas Crueles, Inhumanos o Degradantes; y la Convención sobre los Derechos del Niño.

3 En el párr. $3^{\circ}$ de ese inciso se ha estatuido el procedimiento para que el Congreso adjudique tal valencia a otros tratados y convenciones sobre derechos humanos (naturalmente luego de aprobarlos) más allá de los que la Ley Fundamental nomina primigeniamente. Sobre la base de tal atribución congresal se ha deparado cotización constitucional ex post a la Convención Interamericana sobre Desaparición Forzada de Personas, por conducto de la Ley 24.820, publicada el 29 de mayo de 1997; y a la Convención sobre la Imprescriptibilidad de los Crímenes de Guerra y de los Crímenes de Lesa Humanidad, por medio de la Ley 25.778, publicada el 3 de setiembre de 2003. 
que hacen que la tradicional figura de la 'pirámide' en la que su vértice superior era ocupado en solitario por la Constitución, haya devenido en una especie de 'trapecio' en cuyo plano más elevado comparten espacios en constante retroalimentación la Ley Fundamental y los documentos internacionales sobre derechos humanos con idéntica valía.

El factor citado en último término (dotación de alcurnia constitucional a los instrumentos internacionales sobre la materia mencionada) ha originado significativos efectos directos y secundarios, entre los que pueden incluirse en nómina no exhaustiva: la ampliación cuantitativa y cualitativa del conglomerado de derechos implícitos y explícitos, y la instauración de los principios pro homine o favor libertatis y pro actione, con el consiguiente refuerzo de los criterios hermenéuticos que le vienen adosados: interpretación de buena fe, pacta sunt servanda y los atinentes al objeto y el fin de los tratados; la vigorización de la pauta que determina la imposibilidad de alegar la existencia o inexistencia de normas de derecho interno para dejar de cumplir compromisos internacionales, premisa que - de no ser acatada - acarreará la responsabilidad internacional del Estado.

Un paradigma con semejantes características conduce a la extensión formal y material del parámetro de control de constitucionalidad, en función de lo cual la normativa infraconstitucional debe ser examinada a la luz de la Norma Básica y de los instrumentos internacionales sobre derechos humanos con cotización homóloga a ésta, para verificar si supera satisfactoriamente el test de constitucionalidad.

Paralelamente a la nombrada atribución de jerarquía constitucional a un conjunto de documentos internacionales sobre derechos humanos por parte de la Convención Constituyente de 1994, al que el Congreso ha adicionado ex post otro par de instrumentos, la citada innovación constitucional también ha introducido, inter alia, la exigencia de asegurar el remozado principio de igualdad a través de acciones positivas y la inexcusable implicación de todas las autoridades públicas en esos menesteres, en un esquema jurídico donde tampoco se puede ignorar el torrente axiológico que brinda el imperativo preambular de "afianzar la justicia".

Un trasfondo con tales peculiaridades propicia además el fortalecimiento de la exigibilidad y la justiciabilidad de los derechos, acrecienta pari passu el protagonismo del Poder Judicial y compromete al Estado a volcar todos los esfuerzos y recursos posibles en el cabal cumplimiento de las obligaciones internacionales tomadas en tal ámbito.

Una muestra reciente de la tendencia seguida por nuestro país en materia de derechos humanos -al menos desde la esfera normativa- se configuró el 14 de diciembre de 2007, cuando procedió a ratificar la Convención Internacional para 
la Protección de Todas las Personas contra las Desapariciones Forzadas (adoptada por la Asamblea General de las Naciones Unidas el 20 de diciembre de 2006), depositando el respectivo instrumento ratificatorio en la sede de las Naciones Unidas, en Nueva York. Dicha Convención fue aprobada por medio de la Ley 26.2984 y convirtió a Argentina en el primer país de América y el segundo en el mundo en ratificar tal instrumento, que fue firmado por 71 Estados y requiere de 20 ratificaciones para entrar en vigor internacionalmente. Según explica la Cancillería argentina, "[u] na de sus disposiciones más trascendentes es aquella que consagra la jurisdicción universal para garantizar la obligación de todo Estado Parte de investigar, detener y eventualmente juzgar a toda persona que se encuentre en su territorio, de la que se supone que ha cometido este delito, o de ser el caso a extraditarla, sin que se pueda considerar la desaparición como delito político para rechazar los pedidos de extradición". Añade que viene a llenar "un vacío existente en el derecho internacional tanto en términos de prevención de las violaciones de derechos humanos y de los derechos de las víctimas, así como en cuanto a la obligación de los Estados de investigar y sancionar a los responsables"

La referencia efectuada en el párrafo anterior es sólo un ejemplo más para constatar que la asunción de compromisos internacionales en la órbita de los derechos humanos ni se agotó con la reforma constitucional ni ésta vehículo un hecho aislado, sino que se trata de una política que se mantiene en el tiempo. Ahora bien, la suscripción, la aprobación y la ratificación de documentos de aquel tipo no son meros actos simbólicos sino que generan correlativas obligaciones que el Estado debe cumplir, quedando alcanzados y vinculados en tal misión todos los poderes y órganos públicos, aunque el impacto más fuerte se produce en la magistratura judicial como último refugio en el plano interno para hacer efectivos los derechos fundamentales y, en virtud de la exigencia de agotamiento de los recursos intranacionales, paso previo e ineludible - salvo puntuales excepciones - para acceder a alguna vía transnacional de protección.

$4 \quad$ Boletín Oficial (en adelante, B.O.) de 30 de noviembre de 2007.

5 Cfr. "Derechos Humanos: La Argentina se convirtió hoy en el primer país de América en ratificar la Convención contra las Desapariciones Forzadas", Información para la Prensa $\mathbf{N}^{\circ}$ 519/07, 14 de diciembre de 2007, Ministerio de Relaciones Exteriores, Comercio Internacional y Culto, Fuente: www.cancilleria.gov.ar/portal/prensa. 


\section{En torno al neoconstitucionalismo(s)}

El propio epígrafe que da lugar a estas líneas sugiere que la voz "neoconstitucionalismo" es polisémica ${ }^{6}$, por lo que entre otros aspectos, también se discute si en puridad corresponde aludir a la misma en singular o en plural ${ }^{7}$.

Sea como fuera, se ha advertido que con el nombre de "neoconstitucionalismo" o "constitucionalismo contemporáneo" se hace referencia tanto a un modelo de organización jurídico-política o de Estado de Derecho, como al tipo de teoría del derecho requerido para explicar aquel modelo; e, incluso, cabría hablar de neoconstitucionalismo como ideología, para mentar la filosofía política que justifica la fórmula del Estado Constitucional de Derecho ${ }^{8}$.

En tren de sintetizar las posiciones atinentes a la textura semántica del citado vocablo, una buena propuesta viene diseñada por SASTRE ARIZA, quien se refiere a aquél expresando que se trata de un nuevo modelo jurídico que representa el Estado Constitucional de Derecho, cuya peculiaridad está dada por las características o funciones de algunas Constituciones que aparecen en la segunda postguerra mundial ${ }^{9}$ y que se contraponen a las del constitucionalismo antiguo o decimonónico $^{10}$, lo que - en la acertada visión de FIORAVANTI - supone que aquellas Constituciones "representan el intento de recomponer la gran fractura entre democracia y constitucionalismo" 11 .

Es preciso reiterar que el Estado contemporáneo es Estado Constitucional, en cuyo contexto la Constitución ocupa un lugar central en el sistema jurídico (junto a los instrumentos internacionales universales y regionales básicos en materia de derechos humanos con valencia homóloga a la de la Carta Fundamental) y ostenta fuerza normativa.

$6 \quad$ Ver sobre el punto: BAZÁN, Víctor, "Neoconstitucionalismo e inconstitucionalidad por omisión”, La Ley, T² 2005-F, Buenos Aires, pp. 775/793.

7 De hecho, una obra colectiva sobre el particular, editada por Miguel Carbonell y que cuenta con aportes de distinguidos estudiosos de dicho modelo, deja al desnudo la raíz del problema. Nos referimos justamente a Neoconstitucionalismo(s), Madrid: Trotta - Universidad Nacional Autónoma de México, 2003. Por razones prácticas, y en tanto sólo realizaremos una breve aproximación al punto -que nos impide indagaciones más profundas-, en este trabajo mantendremos la denominación en singular del término en cuestión.

8 PRIETO SANCHÍS, Luis, voz "Neoconstitucionalismo", en CARBONELL, Miguel (coordinador), Diccionario de derecho constitucional, México, D.F.: Edit. Porrúa y Universidad Nacional Autónoma de México (Instituto de Investigaciones Jurídicas), 2002, p. 420.

9 Por ejemplo, en un primer ciclo las de Italia (1947) y Alemania (1949) y más tarde las de Portugal (1976) y España (1978).

10 SASTRE ARIZA, Santiago, "La ciencia jurídica ante el neoconstitucionalismo", en Neoconstitucionalismo(s), cit. en nota 7, p. 239.

11 FIORAVANTI, M., Constitución. De la antigüedad a nuestros días [1999], trad. de M. Martínez Neira, Madrid: Trotta, 2001, p. 163; cit. por SASTRE ARIZA, Santiago, ídem nota anterior. 
Ligado estrechamente al Estado Constitucional, el neoconstitucionalismo ha modificado, inter alia, el marco teórico del derecho constitucional, surgiendo - en cuanto a lo que aquí interesa- una nueva dogmática constitucional caracterizada por la complejización del Derecho, el que también se tornó menos previsible, permitiendo que en el terreno de la interpretación constitucional gane espacio la técnica de la ponderación de valores, principios y conceptos jurídicos indeterminados, sobre la -hasta entonces - cuasi exclusiva labor de subsunción a la que los jueces estaban principalmente ceñidos.

Lo anterior no importa omitir sin más la utilidad que específicamente en la dimensión de los derechos fundamentales puede reportar como enfoque interpretativo de éstos su armonización o ajuste dentro del sistema general de derechos, tal como postula Nogueira Alcalá, para resguardar la unidad de dicho modelo que tenga como puntos de partida y llegada la integridad y la unidad de la persona humana y de la dignidad inherente a la misma ${ }^{12}$.

De cualquier modo, y como ello no siempre es posible de realizar, cuando tal inviabilidad adviene, se acrecienta el margen de acción de la ponderación (“bilanciamento" o "balancing"), asociada al principio de razonabilidad, como método apropiado para formular un "enunciado de preferencia condicionada" ${ }^{13}$ o trazar una jerarquía axiológica móvil, útil para el caso concreto pero que no impide una respuesta distinta en otro supuesto.

La teoría de la argumentación viene a prestar un significativo servicio a la judicatura al convertirse en un elemento útil en la interpretación constitucional, justamente porque -como acota Barroso - existen hipótesis (por ejemplo, ante cláusulas de contenido abierto, normas de principio y conceptos indeterminados) en las que el fundamento de legitimidad de la actuación judicial se transfiere al proceso argumentativo, donde el magistrado debe demostrar racionalmente que la solución propuesta es la que realiza más adecuadamente la voluntad constitucional ${ }^{14}$.

En ese sentido, Prieto Sanchís puntualiza que en el ámbito descripto se reclama entre otras cosas una depurada teoría de la argumentación capaz de garantizar la racionalidad y de suscitar el consenso en torno a las decisiones judiciales, sentido que tiene -a su criterio - la ponderación rectamente entendida ${ }^{15}$. Según explica, los

12 NOGUEIRA ALCALÁ, Humberto, Lineamientos de interpretación constitucional y del bloque constitucional de derechos, Santiago de Chile: Librotecnia, 2006, pp. 371/372.

13 Prieto Sanchís, Luis, "Neoconstitucionalismo y ponderación judicial", en Neoconstitucionalismo(s), cit. en nota 7, p. 142.

14 Barroso, Luís Roberto, "O começo da história. A nova interpretação constitucional e o papel dos princípios no direito brasileiro", en AA.VV., Visión iberoamericana del tema constitucional, Fundación Manuel García-Pelayo, Caracas, 2003, p. 86.

15 PRIETO SANCHÍs, Luis, "Neoconstitucionalismo y ponderación judicial", en 
rasgos salientes de la nueva teoría del derecho, que encarna el neoconstitucionalismo, son: omnipresencia de la Constitución en todas las áreas jurídicas y en todos los conflictos mínimamente relevantes, en lugar de espacios exentos en favor de la opción legislativa o reglamentaria; más principios que reglas; más ponderación que subsunción; omnipotencia judicial en lugar de autonomía del legislador ordinario; y, por último, coexistencia de una constelación plural de valores, a veces tendencialmente contradictorios, en lugar de homogeneidad ideológica alrededor de un puñado de principios coherentes entre sí y en torno, sobre todo, a las sucesivas opciones legislativas ${ }^{16}$.

\section{Otros rasgos que tipifican el escenario jurídico argentino}

\section{A) Constitucionalización y desvirtuación constitucional}

Lo expuesto en el tándem de apartados anteriores lleva a pensar en una "constitucionalización" del sistema jurídico, en los términos planteados por Guastini, quien a su tiempo se ha encargado de reconocer que al respecto se ha servido de alguna sugerencia de Favoreu ${ }^{17}$. Aquel autor visualiza a la constitucionalización como "un proceso de transformación de un ordenamiento al término del cual éste resulta totalmente 'impregnado' por las normas constitucionales” ${ }^{18}$. Luego amplía el alcance conceptual de tal posición afirmando que

\footnotetext{
un ordenamiento jurídico constitucionalizado se caracteriza por una Constitución extremadamente invasora, entrometida ("pervasiva", "invadente" en el texto italiano), capaz de condicionar tanto la legislación como la jurisprudencia y el estilo doctrinal, la acción de los actores políticos, así como las relaciones sociales ${ }^{19}$.
}

Nutriéndonos de tales apreciaciones, y extrapolándolas a las particularidades del caso argentino, podríamos decir que la reforma de 1994 - ideada para operar en un Estado Constitucional de Derecho - ha acentuado una constitucionalización desde el plano normológico, frente al que -casi automáticamente - en no pocas facetas se ha generado un correlativo proceso de desvirtuación constitucional en la dimensión fáctica, lo que se verifica en un conjunto de temas complejos y de actualidad, algunos de los

\footnotetext{
Neoconstitucionalismo(s), cit. en nota 7, p. 157.

16 Ibíd., pp. 131/132.

17 GUASTINI, Riccardo, “La ‘constitucionalización’ del ordenamiento jurídico: el caso italiano”, trad. de José María Lujambio, Estudios de teoría constitucional, $1^{a}$ reimpr., Doctrina Jurídica Contemporánea, Fontamara, México, D.F., 2003, p. 153.

18 Ídem.

19 Ídem.
} 
cuales deberán ser resueltos en definitiva por la Corte Suprema.

Aludimos, por ejemplo, a la validez constitucional de la modificación que, por conducto de la Ley $26.080^{20}$, el Congreso introdujo a la normativa del Consejo de la Magistratura (Ley 24.93721), reduciendo su número de integrantes y adjudicando al estamento político una mayoría decisiva en cuestiones medulares como la designación de los magistrados judiciales y la activación del botón de arranque del procedimiento para su destitución; o el siempre controvertido tema de los decretos de necesidad y urgencia, la delegación legislativa y la promulgación parcial de leyes, ámbito en el que se dictó la Ley $26.122^{22}$, que tiene por objeto regular el trámite y los alcances de la intervención del Congreso, donde se requiere dictamen de la Comisión Bicameral Permanente ${ }^{23}$, respecto de los "decretos" que en el marco de aquellas tres cuestiones dicta el Poder Ejecutivo.

Otro punto que marca la desvirtuación o erosión constitucionales en la vertiente fáctica radica en el no infrecuente incumplimiento por el Legislativo del desarrollo de los mandatos constitucionales a su cargo. Baste recordar que, por ejemplo, en materia de coparticipación federal impositiva tanto el régimen aplicable (a instrumentarse por una ley convenio con el Senado como Cámara de origen), como la reglamentación del organismo fiscal federal mencionados por el art. 75 , inc. $2^{\circ}$, debieron haber sido establecidos antes de la finalización del año 1996, de acuerdo con la disposición transitoria sexta, lo que aún no ha ocurrido.

No es precisamente reconfortante constatarlo ni ponerlo de manifiesto, pero es igualmente difícil disimular que la sombra de las omisiones inconstitucionales traducibles en la falta de desenvolvimiento legislativo de varios aspectos contenidos en la letra de la Constitución, continúa siendo frondosa en el escenario jurídico nacional.

En síntesis, tomando ilustrativamente sólo un par de sectores temáticos, se constata que órganos creados por la Constitución para mejorar la calidad institucional, por ejemplo, el Consejo de la Magistratura destinado a transparentar la selección de magistrados judiciales inferiores a la Corte Suprema, o institutos concebidos para atenuar el presidencialismo ("prohibición" de la delegación legislativa o del dictado por el Ejecutivo de disposiciones de carácter legislativo ${ }^{24}$ ), quedan distorsionados por la reglamentación infraconstitucional; sin olvidar por su parte, claro está, las pretericiones inconstitucionales que se acumulan al no desarrollar legislativamente

20 B.O. de 27 de febrero de 2006.

21 B.O. de 6 de enero de 1998, texto ordenado por el Decreto 816/99 (B.O. de 30 de julio de 1999) y sus modificatorias. Su correctiva es la Ley 24.939 (B.O. de 6 de enero de 1998).

22 B.O. de 28 de julio de 2006.

23 Prevista en los arts. 99, inc. $3^{\circ}$, y 100, incs. 12 y 13, de la Constitución Nacional (CN).

24 Respectivamente, arts. 76 y 99 , inc. $3^{\circ}$, de la CN. 
preceptos contenidos en la Ley Fundamental. En otras palabras, por uno u otro caminos queda desvirtuada u opacada la supremacía constitucional.

\section{B) Mayor demanda al Poder Judicial}

Aun a riesgo de deslizarnos hacia afirmaciones que suenan a lugares comunes, no es difícil verificar cómo el Poder Legislativo de la Nación se repliega y no asume esferas competenciales que le corresponden de modo específico. Por supuesto, al tiempo que se retrae en algunos aspectos o - según la lectura de algunos analistas políticos - se limita a funcionar como intermediario legislativo del Poder Ejecutivo en otros, éste gana espacios, se acentúa la "crisis de representatividad", se volatiliza la división de poderes y paulatinamente se pierde en calidad institucional.

Sin intención alguna de exhaustividad, ello puede comprobarse - sólo por citar algunos ejemplos relativamente recientes - con la Ley $26.124^{25}$, que sustituye al art. 37 de la Ley $24.156^{26}$ de Administración Financiera y de los Sistemas de Control del Sector Público Nacional, y que acuerda al Jefe de Gabinete de Ministros la facultad de disponer las reestructuraciones presupuestarias que considere necesarias dentro del total aprobado por cada ley de presupuesto, quedando comprendidas las modificaciones que involucren a gastos corrientes, gastos de capital, aplicaciones financieras y distribución de las finalidades, exceptuándolo de lo establecido en el art. 15 de la Ley 25.91727; o con la Ley 26.135 ${ }^{28}$, que, sin perjuicio de la facultad derogatoria del Poder Legislativo, ratificó en el Poder Ejecutivo Nacional, a partir del 24 de agosto de 2006, por el plazo de tres años y con arreglo a las bases oportunamente fijadas por el Congreso, la totalidad de la delegación legislativa sobre materias determinadas de administración o situaciones de emergencia pública, emitidas con anterioridad a la reforma constitucional de 1994, cuyo objeto no se hubiese agotado por su cumplimiento.

Esa retracción parlamentaria y la traslación al Poder Judicial de multiformes cuestiones, muchas de las cuales éste no está en capacidad material ni jurídica de resolver, hace que se acreciente ostensiblemente la labor de la judicatura.

Por cierto, esto último se inscribe también en la paradoja que se delineado acertadamente expresando que aunque se profundice cada vez más una visión crítica y exista una desconfianza creciente respecto del sistema de administración de justicia,

\footnotetext{
25 B.O. de 8 de agosto de 2006 .

26 B.O. de 29 de octubre de 1992.

27 B.O. de 25 de agosto de 2004. Tal normativa trata del "Régimen Federal de Responsabilidad Fiscal".

28 B.O. de 24 de agosto de 2006.
} 
cada día aumenta la demanda por la justicia ${ }^{29}$. En otras palabras, mientras mayor es la crítica contra dicho sistema, mayor es también el requerimiento de justicia por parte de la población.

Morello coincide en dicho diagnóstico y, con su habitual claridad y maestría, ha calificado a la cuestión como "otra de nuestras paradojas", presentándola como sigue:

Las dudas o desconfianza que agrieta el consenso no empece a que el ciudadano, frente a situaciones de lesión o incerteza de sus derechos y garantías, se vuelque como usuario o consumidor de la justicia e invada los tribunales de demandas o solicitudes -fuertemente al amparo y, dentro de él, las medidas cautelares - descontando que sólo los jueces le brindarán la tutela efectiva que promete la Constitución a través del proceso justo ${ }^{30}$.

\section{El rol de la magistratura judicial}

Frente al escenario descripto es obvio que los jueces y, fundamentalmente la Corte Suprema como cabeza de Poder, tienen una ardua labor por delante para cumplir con la responsabilidad que la forma republicana de gobierno, la democracia y el Estado Constitucional les demandan.

Por su parte, la creciente evolución del derecho internacional de los derechos humanos diversifica los retos que se posan sobre la magistratura judicial, entre los que se cuenta la imprescindibilidad de manejar una multiplicidad de fuentes (otrora inexistentes o con una carga preceptiva que, aunque antijurídicamente, era quizá entonces "posible" de mediatizar) y de reestudiar diversas categorías jurídicas a la luz de las pautas internacionales.

Naturalmente, la inobservancia de aquellas obligaciones en el plano transnacional generará la responsabilidad estatal internacional, que resultará agravada si el incumplimiento de que se trate vehicula una infracción - por acción u omisión - a normas iusinternacionales fundamentales.

En este juego de conexiones y articulaciones entre el derecho interno y el derecho internacional de los derechos humanos, no puede pasar inadvertido que, por caso, algunas irradiaciones del art. 29 de la Convención Americana sobre Derechos

29 Cfr. BOLÍVAR, Ligia, “Justicia y acceso. Los problemas y las soluciones”, Revista del Instituto Interamericano de Derechos Humanos, $\mathrm{N}^{\text {os. }}$ 32-33, Edición especial sobre 'Acceso a la Justicia', per. julio 2001-junio 2002, Instituto Interamericano de Derechos Humanos, San José de Costa Rica, p. 72.

30 MORELLO, Augusto M., La Corte Suprema en el sistema político, Buenos Aires: Librería Editora Platense y LexisNexis, 2005, p. 163, nota 2. 
Humanos (en lo sucesivo, CADH) quedan plasmadas en ciertos patrones hermenéuticos por conducto de los cuales ninguna disposición de la Convención puede ser interpretada en el sentido de limitar el goce y el ejercicio de cualquier derecho o libertad que pueda estar reconocido de acuerdo con las leyes de cualquiera de los Estados Partes o de acuerdo con otra convención en que sea parte uno de dichos Estados (inc. 'b'); o no puede serlo para excluir otros derechos y garantías que son inherentes al ser humano o que se derivan de la forma democrática representativa de gobierno (inc. 'c').

Lo expuesto apunta a constatar que ante un conflicto de interpretación o aplicación jurídicas entre una norma internacional de derechos humanos y otra interna sobre la materia, deberá en toda ocasión optarse por la solución que de modo más acabado y efectivo brinde mayor protección a los derechos humanos en juego, sea que aquélla se nutra de una fuente doméstica o de una proveniente del plano internacional.

Ello nos conduce al postulado pro homine que, según PINTO, constituye un criterio hermenéutico que informa todo el derecho de los derechos humanos, en virtud del cual se debe acudir a la norma más amplia, o a la interpretación más extensiva, cuando se trata de reconocer derechos protegidos e, inversamente, a la norma o a la interpretación más restringidas cuando se trata de establecer restricciones permanentes al ejercicio de los derechos o de suspenderlos en forma extraordinaria ${ }^{31}$.

En síntesis, tal estándar activa la necesidad de funcionalizar el principio de protección integral de la persona humana, alimentado por la premisa que indica que Constitución e instrumentos internacionales sobre derechos humanos forman un cuerpo jurídico que orienta su vigencia hacia un mismo sustrato axiológico.

Todos los factores señalados se conjugan para exigir un aggiornamento de la estructura de pensamiento del juez y de su posicionamiento frente a ciertas causas dilemáticas. En el fondo, se trata de un problema de cultura jurídica (que naturalmente involucra también a los litigantes y demás operadores jurídicos) y que impone al magistrado preparación científica y apertura mental ante la mencionada complejidad cuantitativa y cualitativa de fuentes jurídicas; permeabilidad y no refracción o misoneísmo frente a los cambios; consecuente abandono de atavismos y prejuicios jurídicos que, por citar un ejemplo, le deje emigrar de los moldes decimonónicos que imponían casi exclusivamente la subsunción, para emplear otras herramientas (por ejemplo, la armonización o ajuste de derechos fundamentales, o la pondera-

31 PINTO, Mónica, "El principio pro homine. Criterios de hermenéutica y pautas para la regulación de los derechos humanos", en ABREGÚ, Martín y COURTIS, Christian (compiladores), La aplicación de los tratados sobre derechos humanos por los tribunales locales, Centro de Estudios Legales y Sociales, Buenos Aires: Editores del Puerto, 1997, p. 163. 
ción complementada con alguna dosis subsuntiva) que pueden reportar beneficios a la labor hermenéutica; e, inter alia, la visualización del proceso de interpretación jurídica no como mera aplicación normativa mecánica, sino como creación del derecho, en un equilibrado activismo, que sin convertirlo en un juez Hércules o ideal, le permita asumir la conciencia moral del momento histórico que le toca vivir y protagonizar $^{32}$ como importante reducto para la defensa y efectivización de los derechos fundamentales.

Ciertamente entonces, converge una serie de ingredientes que impone un replanteamiento del rol del juez y lo coloca no infrecuentemente ante la exigencia de acometer una relectura de diversas cuestiones jurídicas no sólo ya a la luz de rígidos parámetros del proceso civil, sino de los postulados del derecho constitucional, el procesal constitucional y el internacional de los derechos humanos, incumbencias en constante interacción ${ }^{33}$.

En esa línea se inscribe la necesidad de llevar adelante una interpretación conforme no sólo a la Constitución sino también al derecho internacional de los derechos humanos, asumiendo como realidad incuestionable la renovación del sistema de fuentes del derecho y la extensión formal y material del parámetro de control de constitucionalidad, para cuya configuración ha contribuido el firme desarrollo del derecho internacional de los derechos humanos y la nombrada adjudicación de jerarquía constitucional, originaria o derivada, a un significativo repertorio de instrumentos internacionales sobre aquella materia.

Retomando algunos aspectos que anticipábamos, se observa un considerable aumento del tenor de exigencia impuesto a la judicatura en la faena de argumentación de sus sentencias, principalmente de aquellas con trascendencia constitucional, como presupuesto de su propia legitimidad institucional. Lejos de permanecer ajena a tal situación, la Corte - como cabeza de Poder y órgano de cierre de la jurisdicción constitucional - debe redoblar esfuerzos en la justificación racional de sus decisiones, no por esnobismo constitucional sino para reforzar el calibre de las posiciones jurisdiccionales que, en casos complejos, generen precedentes imbuidos de ejemplaridad.

\footnotetext{
32 Sobre estas últimas consideraciones, ver el interesante trabajo de CÁRDENAS GRACIA, Jaime, "Los principios y su impacto en la interpretación constitucional y judicial", en FERRER MAC-GREGOR, Eduardo (coordinador), Interpretación constitucional, T ${ }^{\circ} \mathrm{I}$, México, D.F.: Edit. Porrúa y Universidad Nacional Autónoma de México (Instituto de Investigaciones Jurídicas), 2005, pp. 261/279, en esp. pp. 278/279.

33 Una aproximación al particular puede verse en BAZÁN, Víctor, "Algunos problemas y desafíos actuales de la jurisdicción constitucional en Iberoamérica", Anuario de Derecho Constitucional Latinoamericano 2007, $\mathrm{T}^{\circ} \mathrm{I}$, Montevideo: Fundación Konrad Adenauer, pp. 37/61; y "Derecho Procesal Constitucional: estado de avance, retos y prospectiva de la disciplina”, La Ley. Suplemento de Derecho Constitucional, Buenos Aires, 27 de agosto de 2007, pp. $1 / 21$.
} 


\section{La Corte Suprema, los cambios en su composición y algunos intentos por "marcar su territorio"}

Preliminarmente, debe recordarse que en los últimos años se han producido varios movimientos en la integración del Alto Tribunal. Tales innovaciones han resultado determinantes para favorecer el proceso de rediseño institucional que viene experimentando últimamente.

En el contexto anunciado, se concretaron las renuncias de los doctores Bossert y Nazareno, quienes fueron reemplazados, respectivamente, por los ministros Maqueda y Zaffaroni. Tampoco están ya los doctores López (quien falleció luego de alejarse del Tribunal) y Moliné O’Connor (removido por juicio político). Una de tales vacantes fue cubierta por la doctora Highton de Nolasco; la restante, por la doctora Argibay. Igualmente, dimitió el doctor Vázquez y se incorporó el doctor Lorenzetti (hoy presidente de la Corte).

Por su parte, en junio de 2005 el doctor Belluscio renunció a su cargo con efecto a partir del $1^{\circ}$ de septiembre del mismo año. Días después, concretamente el 28 de este último mes, el doctor Boggiano fue destituido por el Senado de la Nación como desenlace del enjuiciamiento político seguido en su contra.

En consecuencia, la Corte ha quedado integrada con los siguientes siete ministros: Lorenzetti, Highton de Nolasco, Petracchi, Fayt, Maqueda, Zaffaroni y Argibay.

En el futuro, cuando se produzcan vacantes definitivas en los cargos ocupados por los actuales componentes del Tribunal, las mismas no serán cubiertas hasta que se alcance la cantidad de cinco integrantes, la que, por imperio de la Ley $26.183^{34}$, constituye el nuevo número institucional que definitivamente deberá tener el Tribunal ${ }^{35}$.

34 La ley fue sancionada el 29 de noviembre de 2006, promulgada el 15 de diciembre de 2006 y publicada en fecha 18 de diciembre de 2006. A lo largo de la historia, el número de componentes del Tribunal ha ido variando. Así, por la Ley 27, de 13 de octubre de 1862 (publicada en R.N. $1.857 / 62$, p. 496), se estableció que "[l]a Justicia Nacional se ejercerá por medio de una Corte Suprema de Justicia, compuesta de cinco Ministros y un Procurador General" (remarcado agregado); posteriormente, la Ley 15.271 (BO de 9 de febrero de 1960) llevó la cantidad de ministros de la Corte a siete; luego, la Ley 16.895 (BO de 7 de julio de 1966) la fijó nuevamente en cinco; mientras que la Ley 23.774 (BO de 16 de abril de 1990) la elevó a nueve. Así, hasta llegar a la Ley 26.183 aludida en el texto y de cuyo contenido se dará breve noticia en la nota siguiente.

35 El art. 2 de la citada Ley 26.183 incorpora como art. 21 del Decreto-Ley 1.285/58, texto según la citada Ley 16.895, un precepto que en lo que aquí interesa determina que "[1]a Corte Suprema de Justicia de la Nación estará compuesta por cinco (5) jueces". Por su parte, el art. 3 de la ley que reseñamos contiene una disposición transitoria, que reza: "La reducción de los miembros de la Corte Suprema de Justicia de la Nación dispuesta por el artículo anterior, operará del siguiente modo: Desde la entrada en vigencia de la presente ley se reducirá transitoriamente a siete (7) el número de jueces que la integran. A partir de dicha reducción, las decisiones de la 
Con sus nuevos componentes, todo parece indicar que el Tribunal intenta diferenciarse de la "vieja Corte" (entonces de nueve miembros); en realidad, procura separarse específicamente de lo que se dio en llamar la "mayoría automática" (cinco de aquellos nueve jueces), que acompañó en numerosos fallos la política del ex presidente Menem, en cuya gestión -y por conducto de la Ley 23.774 (citada en nota 34 a pie de página) - justamente se llevó a nueve el número de ministros que a partir de entonces comenzaron a integrarla.

Desde su remozada conformación la Corte busca "relegitimarse", ganar credibilidad, dar muestras a la sociedad de independencia y fortaleza, idear alternativas de solución para un número absolutamente inmanejable de causas tramitadas en su seno y solidificar su rol político-institucional "marcando su terreno" como cabeza del Poder Judicial, faceta esta última que nos tiende el puente hacia el tema que abordaremos a continuación.

\section{El proceso de rediseño de su identidad institucional}

\section{Liminar}

En el particular contexto descripto, la Corte se encuentra en trance de diseñar una nueva identidad institucional y de perfilar un remozado esquema de jurisdicción constitucional.

A continuación, relevaremos las vertientes de la jurisprudencia (fraccionada en dos segmentos: resoluciones de fondo y decisiones relativas a la determinación de su competencia originaria) y de los acuerdos del Tribunal, que confirman la apuesta orientada a alcanzar los señalados propósitos.

Corte Suprema de Justicia de la Nación se adoptarán por el voto mayoritario de cuatro (4) de sus miembros. A posteriori, en oportunidad de producirse una vacante definitiva se reducirá transitoriamente a seis (6) el número de jueces de la Corte Suprema de Justicia de la Nación. En dicho período las decisiones de la Corte Suprema de Justicia de la Nación se adoptarán por el voto mayoritario de cuatro (4) de sus miembros. Producida una nueva vacante definitiva, se reducirá a cinco (5) el número de jueces que la componen. Las decisiones se adoptarán por el voto de la mayoría absoluta de sus miembros". 


\section{Jurisprudencia relativa a decisiones de fondo y a otros pronunciaientos en el marco de la configuración de la competencia originaria de la Corte}

\section{A) Ejercicio del control de constitucionalidad, generación de lazos dialógicos con otros poderes de los Estados Nacional o Provinciales y diversas cuestiones contenidas en fallos institucionales del Tribunal}

En el desarrollo de su tarea de control de constitucionalidad se comprueba que, entre distintos tópicos, el Tribunal utiliza variantes "atípicas" de sentencias constitucionales, modula los efectos de tales pronunciamientos y abre vías de colaboración dialógica con otros poderes de los Estados Nacional o Provinciales. Asimismo, en otros fallos se anima a afrontar complicados asuntos con óptica y actitud institucionales.

En esa dirección se ubican, cada uno en su espectro de incumbencia temática y con sus particularidades fisonómicas, v.gr.: "Itzcovich, Mabel c/ ANSeS s/ reajustes varios" "36, de 29 de marzo de 2005; "Verbitsky, Horacio" ${ }^{37}$, de 3 de mayo de 2005; ${ }^{39}$ Badaro, Adolfo Valentín c/ ANSeS s/ reajustes varios I ${ }^{38}$ y II ${ }^{39}$, , de 8 de agosto de 2006 y de 26 de noviembre de 2007, respectivamente; "Massa, Juan Agustín c/ Poder Ejecutivo Nacional - Dto. 1.570/01 y otro s/ amparo Ley 16.986" ${ }^{\prime 4}$, de 27 de diciembre de 2006; "Rinaldi, Francisco Augusto y otro c/ Guzmán Toledo, Ronal Constante y otra s/ ejecución hipotecaria"41 , de 15 de marzo de 2007; "Rosza, Carlos Alberto y otro s/ recurso de casación”"42, de 23 de mayo de 2007; "Bussi, Antonio Domingo c/ Estado Nacional (Congreso de la Nación - Cámara de Diputados) s/ incorporación a la Cámara de Diputados" ${ }^{3}$, de 13 de julio de 2007; "Mazzeo, Julio

\footnotetext{
36 Fallos, 328:566. Sobre tal decisorio, ver BAZÁN, Víctor, "La Corte Suprema de Justicia argentina y la depuración de su competencia apelada por medio del control de constitucionalidad", Revista Iberoamericana de Derecho Procesal Constitucional, $\mathrm{N}^{\circ}$ 5, enero/junio 2006, Instituto Iberoamericano de Derecho Procesal Constitucional, México, D.F.: Edit. Porrúa, pp. 257/287.

37 Fallos, 328:1146.

38 "B.675.XLI, Badaro, Adolfo Valentín c/ ANSeS s/ reajustes varios, de 8 de agosto de 2006 (Fallos, 329:3089).

39 Se trata de un segundo pronunciamiento en la causa identificada en la nota anterior, emitido el 26 de noviembre de 2007.

40 Causa 'M.2771.XLI'.

41 Causa 'R.320.XLII'.

42 Causa 'R.1309.XLII'.

43 Causa 'B.903.XL'.
} 
Lilo y otros s/ recurso de casación e inconstitucionalidad" ${ }^{44}$, de la misma fecha; y "Editorial Río Negro S.A. c/ Provincia del Neuquén s/ acción de amparo" 45 , de 5 de septiembre de 2007.

Seguidamente, haremos breve referencia a cada uno de ellos.

\section{a) "Itzcovich"}

En esta causa declaró por mayoría ${ }^{46}$ la inconstitucionalidad (sobreviniente) del art. 19 de la Ley 24.463 - de "solidaridad previsional" 4 -, que habilitaba un recurso ordinario de apelación ante aquélla respecto de las sentencias definitivas de la Cámara Federal de la Seguridad Social.

Entre otros aspectos dignos de ser resaltados, el enfoque mayoritario es remarcable en tanto representa un eslabón de singular importancia en la línea jurisprudencial del Tribunal, favorable a eludir algunas detracciones a la tarea de control de constitucionalidad en temas otrora impenetrables jurisdiccionalmente por entrañar cuestiones políticas no justiciables ${ }^{48}$, sometiendo en este caso a fiscalización constitucional la facultad legislativa establecida en el art. 117 de la Ley Fundamental de regular la competencia por apelación del Tribunal.

Por su parte, y para graduar temporalmente los efectos de la declaración de inconstitucionalidad, advirtió que la autoridad institucional dimanante de su pronunciamiento no privaba de validez a los actos procesales cumplidos ni dejaba sin efecto lo actuado de conformidad con las leyes en vigor, toda vez que la aplicación en el tiempo de los nuevos criterios jurisprudenciales habría de ser presidida por una especial prudencia con el objeto de que los logros propuestos no se vieran malogrados en ese trance (consid. 15 de la mayoría). En línea con ello, y para evitar la retrogradación de los procesos, decidió que las causas en las que ya hubiera sido notificada la sentencia de Cámara, con anterioridad al momento en que el fallo "Itzcovich" quedara firme, debían continuar su trámite con arreglo a la norma cuya inconstitucionalidad determinaba (id. consid.).

$\overline{44}$ Causa 'M.2333.XLII y otros'.

45 Causa 'E.1.XXXIX'.

46 El voto que encabeza la sentencia fue suscripto por los ministros Petracchi, Fayt y Highton de Nolasco. Por su parte, y según sus votos, se expidieron los doctores Maqueda y Zaffaroni, en forma conjunta, y Lorenzetti, de manera individual (todos éstos, concurrentemente con la decisión mayoritaria). Finalmente, en sendas disidencias parciales, se pronunciaron los jueces Belluscio, Boggiano y Argibay

47 B.O. de 30 de marzo de 1995.

48 Queda a salvo el criterio que el doctor Belluscio expuso en su disidencia, al pronunciarse en contra de tal posibilidad fiscalizatoria por considerarla un poder discrecional del Congreso (ver consid. $3^{\circ}$, párr. $2^{\circ}$ ). 
Es preciso acotar que pocos días después del pronunciamiento, el Congreso de la Nación sancionó la Ley $26.025^{49}$ por la cual abrogó el nombrado art. 19 de la Ley 24.463. Obviamente, el fallo aceleró los tiempos e indujo el nacimiento en sede parlamentaria de semejante respuesta legislativa, consistente con el temperamento premoldeado judicialmente.

\section{b) "Verbitsky"}

Puso aquí de manifiesto una visión amplia y despojada de formalismos en materia de legitimación procesal activa, al admitir por primera vez un hábeas corpus correctivo y colectivo articulado en amparo de todas las personas privadas de su libertad en jurisdicción de la Provincia de Buenos Aires detenidas en establecimientos penales y comisarías sobrepoblados, a pesar de que legal y constitucionalmente su alojamiento debería desarrollarse en centros de detención especializados. Debe advertirse que el caso reconoce algún parentesco con lo resuelto por el Tribunal (con otra composición) en "Mignone, Emilio Fermín s/ acción de amparo" ${ }^{50}$ de 9 de abril de 2002, aunque allí la pretensión fue incoada primigeniamente como amparo y recanalizada procesalmente como hábeas corpus.

En "Verbitsky", por mayoría", la Corte reivindicó su papel institucional y dictó un fallo relevante, entre otros aspectos, porque ${ }^{52}$ activismo judicial mediante diseñó un remedio jurisdiccional para combatir las omisiones contrarias a la Constitución y a los tratados internacionales con valencia homóloga en que incurren las autoridades provinciales competentes en materia de ejecución penal, y que resultan violatorias, v.gr., del art. 18 de la Constitución Nacional (en adelante también CN) y de los arts. XXV de la Declaración Americana de los Derechos y Deberes del Hombre (todo individuo "tiene derecho también a un tratamiento humano durante la privación de su libertad"), 10 del Pacto Internacional de Derechos Civiles y Políticos - PIDCP - (“toda persona privada de libertad será tratada humanamente y con el respeto debido a la dignidad inherente al ser humano") y 5 , inc. $2^{\circ}$, de la CADH (norma con similar configuración léxica y contenido semántico a la del Pacto citado en último término) - ver consid. 39 de la mayoría-.

$\overline{49}$ B.O. de 22 de abril de 2005 .

50 Fallos, 325:524. Los alineamientos en el Tribunal fueron los siguientes: la mayoría estuvo compuesta por los doctores Nazareno, Moliné O’Connor y López; en sendos votos particulares, aunque coincidentes en lo sustancial, lo hicieron los ministros Boggiano y Bossert; y, por su parte, los jueces Fayt y Petracchi, en voto conjunto, concurrieron con la mayoría.

51 La mayoría quedó conformada por los ministros Petracchi, Maqueda, Zaffaroni, Higbton de Nolasco y Lorenzetti. Por su parte, en disidencia se expidió el doctor Boggiano y, también disidentemente aunque sólo en forma parcial, lo hicieron por separado los ministros Fayt y Argibay. 
Emitió una sentencia exhortativa multilateral, englobando en sus requerimientos a los tres poderes del Estado Provincial, por conducto de la cual decidió:

Declarar que las Reglas Mínimas para el tratamiento de Reclusos de las Naciones Unidas, recogidas por la Ley $24.660^{52}$, configuran el estándar básico infranqueable al que debe sujetarse toda detención para que la privación de la libertad ambulatoria legítimamente impuesta por un órgano judicial competente se adapte a los lineamientos indispensables para preservar la dignidad de la persona humana;

disponer que la Suprema Corte de Justicia de la Provincia de Buenos Aires, a través de los jueces competentes, haga cesar en el término de sesenta (60) días la detención en comisarías de la provincia de menores y enfermos;

instruir al mencionado órgano judiciario y a los tribunales de todas las instancias de la provincia para que, en sus respectivas competencias, con la urgencia del caso, hagan cesar toda eventual situación de agravamiento de la detención que importe un trato cruel, inhumano o degradante o cualquier otro susceptible de acarrear responsabilidad internacional al Estado Federal;

ordenar al Poder Ejecutivo de la Provincia de Buenos Aires que, por intermedio de la autoridad de ejecución de las detenciones, remita a los jueces respectivos, en el término de treinta (30) días, un informe pormenorizado, en el que consten las condiciones concretas en que se cumple la detención (características de la celda, cantidad de camas, condiciones de higiene, acceso a servicios sanitarios, etc.), a fin de que éstos puedan ponderar adecuadamente la necesidad de mantener la detención, o bien, dispongan medidas de cautela o formas de ejecución de la pena menos lesivas. Asimismo, entendió pertinente que se informara en el plazo de cinco (5) días toda modificación relevante de la situación oportunamente comunicada;

disponer que cada sesenta (60) días el Poder Ejecutivo de la Provincia de Buenos Aires informe a la Corte Nacional las medidas que adopte para mejorar la situación de los detenidos en todo el territorio de la provincia;

exhortar a los Poderes Ejecutivo y Legislativo de la Provincia de Buenos Aires a adecuar su legislación procesal penal en materia de prisión preventiva y excarcelación y su legislación de ejecución penal y penitenciaria, a los estándares constitucionales e internacionales; y encomendar al Poder Ejecutivo de la Provincia de Buenos Aires que, a través de su Ministerio de Justicia, organice la convocatoria de una mesa de diálogo a la que invitaría a la accionante (recuérdese que la demanda fue articulada por el Sr. Verbitsky, representante legal del Centro de Estudios Legales y Sociales -CELS-), y restantes organizaciones presentadas como amici curiae, sin perjuicio de integrarla con otros sectores de la sociedad civil, debiendo informar a la Corte cada sesenta días de los avances logrados.

$\overline{52}$ B.O. de 16 de julio de 1996. 


\section{c) "Badaro I y II"}

Aunque abandonemos por un instante la línea cronológica, por razones metodológicas corresponde examinar aquí en forma conjunta ambas sentencias pues ellas corresponden al mismo caso. Por tanto, y para distinguirlas, las hemos identificado como "Badaro I" y "Badaro II".

\section{c.1.) "Badaro I"}

Enfatizó en forma unánime53 que la efectividad de la cláusula constitucional sobre la movilidad jubilatoria (art. 14 bis) debe resguardarse legislando sobre el punto (consid. $6^{\circ}$ ). Convergentemente expresó que el precepto constitucional de la movilidad se dirige primordialmente al legislador, que es el que tiene la facultad de establecer los criterios que estime adecuados a la realidad, mediante una reglamentación que presenta indudable limitación, ya que no puede alterarla (art. 28) sino conferirle la extensión y comprensión previstas en el texto que la enunció y que manda a asegurarla (consid. 15). Además, puso de manifiesto que la ausencia de aumentos en los haberes del demandante no aparece como el fruto de un sistema válido de movilidad, pues la finalidad de la garantía constitucional en juego es acompañar a las prestaciones en el transcurso del tiempo para reforzarlas a medida que decaiga su valor con relación a los salarios de actividad, de lo que extrajo que la falta de corrección en una medida que guarde relación con el deterioro sufrido, como acontece en autos, configura un apartamiento del mandato del art. 14 bis de la Constitución Nacional (sobremarcado agregado; consid. 13).

Precisó además que no sólo es facultad sino también deber del legislador fijar el contenido concreto de la garantía constitucional en juego, teniendo en cuenta la protección especial que la Ley Suprema ha otorgado al conjunto de los derechos sociales, ya que en su art. 75, incs. 19 y 23, impone al Congreso proveer lo conducente al desarrollo humano y al progreso económico con justicia social, para lo cual debe

53 Luego del fallo "Badaro I" el Congreso sancionó la Ley 26.198 (B.O. de 10 de enero de 2007), aprobatoria del presupuesto 2007, que reconoció un aumento general del 13\% con vigencia desde el $1^{\circ}$ de enero de 2007 , convalidó los aumentos de los haberes inferiores a $\$ 1.000$ implementados por distintos decretos de necesidad y urgencia y facultó al Ejecutivo para conceder incrementos adicionales, lo cual se concretó por medio del Decreto 1.346/2007 (B.O. de 5 de octubre de 2007) que estableció un aumento general del $12,5 \%$ a partir del $1^{\circ}$ de septiembre de 2007. Del breve repaso anterior se observa claramente que, en definitiva, ninguna de las medidas descriptas previó la razonable movilidad de los beneficios jubilatorios en el período reclamado por el demandante: $1^{\circ}$ de enero de 2002 a 31 de diciembre de 2006; con lo cual quedaba incumplido lo resuelto en "Badaro I". 
legislar y promover medidas de acción positiva que garanticen el pleno goce de los derechos reconocidos, en particular, a los ancianos, norma que descalifica todo accionar que en la práctica lleve a un resultado que afecte tales derechos(consid. 17).

La Corte mostrándose consciente de sus límites advirtió que no era apropiado fijar ella misma sin más la movilidad que cabe reconocer en la causa, pues la trascendencia de esa resolución y las actuales condiciones económicas requieren de una evaluación cuidadosa y medidas de alcance general y armónicas, debido a la complejidad de la gestión del gasto público y las múltiples necesidades que está destinado a satisfacer(consid. 16). Consiguientemente, dispuso llevar a conocimiento de las autoridades que tienen asignadas las atribuciones para efectuar las correcciones necesarias que la omisión de disponer un ajuste por movilidad en el beneficio del actor ha llevado a privarlo de un derecho conferido por la Ley Fundamental, difiriendo su pronunciamiento sobre el período cuestionado por un plazo que resulte suficiente para el dictado de las disposiciones pertinentes (consid. 19).

Compendiando los perfiles del díctum, el Tribunal detectó la omisión legislativa inconstitucional consistente en la falta de disposición de un ajuste por movilidad en el beneficio previsional del actor que había llevado a privarlo de un derecho conferido por la Carta Magna; se abstuvo de adoptar per se la decisión supletoria de la mentada omisión; difirió el pronunciamiento sobre el período cuestionado por un plazo que resultara suficiente para el dictado de las disposiciones pertinentes; y dispuso comunicar al Poder Ejecutivo Nacional y al Congreso de la Nación el contenido de la sentencia a fin de que, en un plazo razonable, adopten las medidas pertinentes para efectuar las correcciones necesarias.

\section{c.2.) "Badaro II"}

Al haber transcurrido un lapso de tiempo prudencial (un poco más de quince meses) sin haber recibido una respuesta específica y satisfactoria sobre el punto ordenado (emisión de reglas adecuadas a la situación del peticionante) ${ }^{54}$, y añadir que el primer fallo dictado en la causa "fue preciso al detallar la omisión legislativa que la Corte había advertido y el daño derivado de ella”, en forma unánime ${ }^{55}$ declaró la

54 Votaron los ministros ministros Petracchi, Highton de Nolasco, Fayt, Maqueda, Zaffaroni y Lorenzetti.

55 Los alineamientos en el Tribunal fueron los siguientes: el voto que encabeza el fallo correspondió a los doctores Highton de Nolasco y Zaffaroni; concurrentemente, con ampliación de fundamentos, se expidió el doctor Lorenzetti; por su parte, el ministro Fayt también votó de manera coincidente; y, finalmente, la jueza Argibay, si bien concordó con la parte resolutiva propuesta por la mayoría, arribó a ella por camino diverso al propugnar la inconstitucionalidad 
inconstitucionalidad del art. 7 , inc. $2^{\circ}$, de la Ley 24.463 , en el caso, y determinó que la prestación del accionante (que supera los $\$ 1.000$ ) se ajuste, entre el $1^{\circ}$ de enero de 2002 y el 31 de diciembre de 2006, de acuerdo con las variaciones anuales del índice de salarios, nivel general, elaborado por el Instituto Nacional de Estadísticas y Censos, ordenando además a la ANSeS que abone el nuevo haber y practique liquidación de las retroactividades pertinentes más los intereses de acuerdo con la tasa pasiva.

Para arribar a tal solución, y entre otras apreciaciones, argumentó que si bien eran constitucionales los cambios de los regímenes de movilidad, esto es, el reemplazo de un método de determinación de incrementos por otro a los fines de lograr una mejor administración o de dar mayor previsibilidad financiera al sistema de seguridad social, el reconocimiento de esa facultad se encontraba sujeto a una indudable limitación, ya que tales modificaciones no pueden conducir a reducciones confiscatorias en los haberes (consid. 13).

Y como el único aumento en el beneficio jubilatorio del accionante que se dispuso durante el período reclamado (enero de 2002 a diciembre de 2006) era insuficiente para reparar su deterioro, consideró procedente declarar en el caso la inconstitucionalidad del régimen de movilidad aplicable y ordenar su sustitución y el pago de las diferencias pertinentes (consid. 20).

Finalmente, y más allá de la solución puntual adoptada, el Tribunal manifestó que contribuiría a la seguridad jurídica el dictado de una ley que establezca pautas de aplicación permanentes que aseguren el objetivo constitucional relativo a la movilidad de las prestaciones previsionales, pues "una reglamentación prudente de la garantía en cuestión, además de facilitar el debate anual sobre la distribución de recursos y evitar el uso de las facultades discrecionales, permitiría reducir la litigiosidad en esta materia, que ha redundado en menoscabo de los derechos de los justiciables y del adecuado funcionamiento del Poder Judicial”' (consid. 24).

Por tal motivo, formuló una nueva exhortación a las autoridades responsables a fin de que examinen dicha problemática. Entre otros aspectos salientes, la resolución supuso - ante la omisión legislativa - la fijación de una regla para el caso concreto no exenta de contenido aditivo, en cierto punto similar al temperamento adoptado en la causa que colacionaremos a continuación.

del Decreto 214/02. 


\section{d) "Massa"}

Por mayoría $a^{56}$, emitió una suerte de sentencia interpretativa desestimatoria en el ámbito de la pesificación de los depósitos bancarios dispuesta por el gobierno nacional, rechazando el planteo de inconstitucionalidad que por vía de amparo había formulado el titular de una caja de ahorro en dólares contra el Decreto 214/02 ${ }^{57}$ y sus normas complementarias. En tal sentido, interpretó a ese conjunto normativo como conforme a la Constitución (ponderando las graves consecuencias que una evaluación de la normativa de pesificación contraria a ésta podría producir), aunque paralelamente, con tono activista y en cierto punto aditivo, diseñó un criterio normativo ${ }^{58}$ aplicable al caso (mas con fuerza expansiva hacia otros) al declarar el derecho de la actora a obtener de la entidad bancaria el reintegro de su depósito convertido en pesos a la relación de $\$ 1,40$ por cada dólar estadounidense, ajustado por el Coeficiente de Estabilización de Referencia (C.E.R.) hasta el momento de su pago, más la aplicación de intereses a la tasa del 4\% anual sobre el monto así obtenido.

Varias son las alusiones al carácter y la envergadura institucionales del fallo, además de que la posición mayoritaria aclaró que el Tribunal actuaba como "cabeza del Poder Judicial de la Nación" para decidir de modo definitivo las cuestiones tan largamente discutidas entre los depositantes y las entidades bancarias (consid. $8^{\circ}$ del voto de la mayoría). En esa dirección, se refirió por ejemplo al ejercicio de la "más alta función institucional" que tiene asignada el Tribunal (consid. 9); a que la "respuesta institucional" que adoptaba era el fruto de una decisión consensuada entre los ministros que lo integran, en aras del elevado propósito de poner fin a un "litigio de indudable trascendencia institucional y social" (consid. 10 -conceptos que se repiten en el consid. 11-); y a la "trascendencia institucional" de las cuestiones planteadas (consid. 23).

\footnotetext{
56 B.O. de 4 de febrero de 2002.

57 Algo similar había realizado en "Vizzoti, Carlos Alberto c/ AMSA S.A. s/ despido", de 14 de septiembre de 2004 (Fallos, 327:3677), en el que mudó su criterio anterior y por unanimidad (votaron los doctores Petracchi, Belluscio, Fayt, Boggiano, Maqueda, Zaffaroni y Highton de Nolasco), invalidó constitucionalmente - por irrazonable- el límite a la base salarial, previsto en los párrafos $2^{\circ} \mathrm{y}$ $3^{\circ}$ del art. 245 de la Ley de Contrato de Trabajo (según Ley 24.013 -B.O. de 17 de diciembre de 1991-), para calcular la indemnización por despido incausado. Concretamente, y con un dejo adicional de activismo, al tiempo de desactivar por inconstitucional aquel límite, moduló un criterio normativo aplicable a la causa al determinar per se que correspondía aplicar tal limitación sólo hasta el 33\% de la mejor remuneración mensual, normal y habitual computable.

58 B.O. de 29 de noviembre de 2006.
} 


\section{e) "Rinaldi"}

En este fallo, indudablemente institucional, optó por no declarar la inconstitucionalidad del régimen de refinanciación hipotecaria en el marco de la pesificación de la obligación en moneda extranjera en un contrato de mutuo con garantía hipotecaria de vivienda única y familiar (art. 14 bis de la Ley Fundamental), desestimando el planteo que en tal sentido se dirigía contra la Ley $26.167^{59}$, y que fuera incoado cuando la causa ya se encontraba en poder de la Corte. Dispuso, en definitiva, que en las ejecuciones de mutuos hipotecarios celebrados entre particulares en divisa extranjera y por un monto inferior a $\$ 100.000$, en los que el deudor tenga comprometida su vivienda única y familiar, el reajuste equitativo de las prestaciones al que se refiere el art. 11 de la Ley $25.561^{60}$, no podrá exceder el cálculo que surge de la conversión de un dólar a un peso más el 30\% de la diferencia entre dicha paridad y la cotización libre del dólar a la fecha en que se practique la liquidación, debiendo adicionarse un interés que no sea superior al 2,5\% anual por todo concepto, desde la mora hasta su efectivo pago. Ello, por aplicación de lo previsto en el art. 6 de la Ley 26.167.

En la moción mayoritaria ${ }^{61}$ se sostuvo que ante la posibilidad de que un número muy importante de deudores hipotecarios pudieran ver en peligro la subsistencia de las garantías contempladas por el citado articulo 14 bis constitucional, las medidas legislativas tendientes al afianzamiento de la vivienda familiar - entre las que debía incluirse a las Leyes $25.798^{62}$ y $25.908^{63}$, que habían quedado subsumidas en la Ley 26.167 - obedecían a un propósito de justicia (cfr. Fallos, 249:183), y la razonabilidad de las mayores restricciones que aquéllas imponían al derecho de propiedad del acreedor, debían valorarse en función de la entidad de la crisis que buscaba superarse (consid. 47).

Pese a que todos los jueces que suscribieron el decisorio confluyeron en la solución final aludida supra, transitaron caminos argumentales diversos e incluso dejaron entrever su falta de coincidencia respecto de la ponderación de la validez constitucional de las normas de emergencia para conjurar la crisis económica y social. Así, mientras los jueces Highton de Nolasco y Maqueda consideraron que aquéllas no carecen de la razonabilidad necesaria para sustentar su validez cons-

59 B.O. de 7 de enero de 2002 .

${ }^{60}$ El voto que encabeza la sentencia correspondió a los ministros Highton de Nolasco y Maqueda; concurrentemente, en forma conjunta y coincidiendo con éstos en sus primeros once considerandos, se expidieron los doctores Lorenzetti y Zaffaroni; y, finalmente, la doctora Argibay se expidió por su voto.

61 B.O. de 7 de noviembre de 2003.

62 B.O. de 13 de julio de 2004.

63297 U.S. 288 (1936). 
titucional (consid. 39); los doctores Lorenzetti y Zaffaroni, entendieron que "las restricciones que, con fundamento en la emergencia económica, se discuten en la causa, han constituido un avance intolerable sobre la autonomía privada y la posición contractual" (consid. 17), y que, sin perjuicio de que el Tribunal se pronunció sobre la constitucionalidad de la regla general en "Massa", "resulta evidente que la legislación de emergencia ha avanzado indebidamente sobre lo establecido por las partes, dejando de lado cláusulas pactadas, lo que resulta irrazonable" (id. consid.), aunque concluyeron que devenía inoficiosa la declaración de inconstitucionalidad por existir una solución sustentada en la aplicación de otros principios constitucionales en las actuales circunstancias (consid. 18 y ss.). Con ello, circunvalaron la pertinente tacha de inconstitucionalidad (consid. 13, in fine), utilizando un resorte argumental que ya había sido deslizado por el doctor Lorenzetti en su ampliación de fundamentos en "Massa" (ver consid. 24).

Puede entreverse aquí algún dejo propio de la técnica de la "evitación", empleada en el derecho norteamericano (avoidance doctrine) para eludir el juicio de constitucionalidad de la ley aun teniendo serias dudas acerca de su constitucionalidad y que, aunque naturalmente no fuera hasta entonces desconocida o inaplicada por la Suprema Corte de Justicia de EE.UU. e incluso esbozada por Cooley, quedó expuesta de modo sistemático en las reglas (sobre todo, la $4^{\mathrm{a}}$ y la $7^{\mathrm{a}}$ ) contenidas en el célebre voto particular concurrente de Brandeis a la decisión del Máximo Tribunal norteamericano en "Ashwander v. Tennessee Valley Authority" "64, para plasmar (contando con la adhesión de los jueces Stone, Roberts y Cardozo) un conjunto de pautas que a su criterio, y como recuerda LóPEZ BOFIL, debían orientar la actuación de la Suprema Corte para moderar los alcances de su jurisdicción y sus pronunciamientos ${ }^{65}$.

Retomando la referencia a "Rinaldi", es posible verificar que la carga institucional del pronunciamiento se dispara desde el citado voto concurrente conjunto de los magistrados Lorenzetti y Zaffaroni, quienes catalogan al caso como receptor de "indudable trascendencia institucional" (consid. 12) y dejan en claro que la misión del Tribunal en semejantes supuestos "no es averiguar la verdad, ni practicar silo-

$\overline{64}$ LÓPEZ BOFILL, Héctor, Decisiones interpretativas en el control de constitucionalidad de la ley, Valencia: Instituto Vasco de Administración Pública, Tirant lo Blanch, 2004, pp. 239 y ss.

65 La mayoría quedó conformada por los ministros Lorenzetti, Highton de Nolasco y Maqueda; concurrentemente votó el magistrado Fayt y, por último y en disidencia conjunta, se pronunciaron los doctores Zaffaroni y Argibay. Los dos magistrados citados en último término, separándose de sus colegas, consideraron prudente desechar la inconstitucionalidad del sistema de subrogancias establecido vía resolución por el Consejo de la Magistratura y propiciar, en cambio, un escrutinio riguroso por parte de los tribunales de alzada sobre el desempeño de los jueces subrogantes, a fin de que refuercen el control sobre sus decisiones en los casos en que puedan configurarse perturbaciones a la independencia con que debe funcionar el Poder Judicial (consid. $6^{\circ}$ ). 
gismos, sino adoptar una decisión que permita apaciguar los conflictos, fundándose en argumentos constitucionales razonables, verificables y que tengan en cuenta los consensos sociales vigentes en el momento de tomarla" (consid. 13).

\section{f) "Rosza"}

Se enfrentó a la sensible cuestión de los nombramientos de los denominados "jueces subrogantes", determinando - por mayoría ${ }^{66}$ - la inconstitucionalidad de la Resolución 76/2004 del Consejo de la Magistratura de la Nación, en virtud de la cual había sido designado el magistrado suplente que entendió en el proceso en cuestión, mas confirmó la declaración de validez de las actuaciones cumplidas por aquél al amparo del régimen reputado inconstitucional. Además, en virtud de tal criterio, y con efecto exógeno general, decidió mantener en el ejercicio de sus cargos a quienes hubieran sido designados para ejercer la función jurisdiccional en los tribunales que se encontraban vacantes hasta que cesaren las razones que originaron su nombramiento o hasta que fueran reemplazados, o ratificados, mediante un procedimiento constitucionalmente válido que debería dictarse en el plazo máximo de un año. Por último, dispuso poner la sentencia en conocimiento del Poder Ejecutivo Nacional, el Congreso y el Consejo de la Magistratura.

En el decisorio se visualizan reiteradas alusiones a lo "institucional" ${ }^{\prime 67}$, ya para adjetivar una situación de desorden que se pretende evitar ("caos institucional" - consid. 22 de la mayoría-) o para calificar el vigor y la naturaleza del pronunciamiento que emitía ("la autoridad institucional de este fallo" - consid. 21 de la moción triunfante-). Pero además, se vislumbran, inter alia, los siguientes aspectos: un recorrido argumentativo para diseñar la motivación de un pronunciamiento de magnitud constitucional; el recurso a la ponderación como método de decisión jurídica recomendable en casos complejos; la preconcepción de las consecuencias de la solución jurisdiccional por dispensar; y el ejercicio de la fiscalización constitucional con modulación temporal de los efectos de la resolución.

Así, en la argumentación que construyera aparece explicitada la respuesta que el Tribunal se veía empujado a asumir para resguardar la seguridad jurídica, sortear una eventual retrogradación de innumerables procesos y evitar una situación caótica en el ámbito de la administración de justicia.

$\overline{66}$ Ver para ampliar, BAZÁN, Víctor, "De jueces subrogantes, casos difíciles y sentencias atípicas", Jurisprudencia Argentina, Buenos Aires: LexisNexis, 15 de agosto de 2007, pp. 23/33.

67 Compuesta por los doctores Lorenzetti, Fayt y Argibay. Paralelamente, mediaron el voto concurrente del ministro Zaffaroni y las disidencias conjunta de los magistrados Highton de Nolasco y Petracchi, e individual del doctor Maqueda. 
Por lo demás, llevó adelante su tarea institucional de control de constitucionalidad diagramando una sentencia "atípica" de "mera inconstitucionalidad" con efectos pro futuro, esto es, los articuló cronológicamente para dejar espacio a los Poderes Ejecutivo y Legislativo en orden a que desplieguen sus competencias y fijen un sistema definitivo sobre la materia en discusión que respete los lineamientos exigidos constitucionalmente.

\section{g) "Bussi"}

Mayoritariamente ${ }^{68}$, y en forma paralela a declarar inoficioso todo pronunciamiento de su parte sobre el planteo introducido en la demanda con respecto a la validez de las decisiones de la Cámara de Diputados de la Nación que negaron la incorporación del Sr. Bussi como miembro de dicho Cuerpo; la Corte interpretó la facultad atribuida en el art. 64 de la CN a aquella Cámara para juzgar la validez de las elecciones, derechos y títulos de sus miembros, concluyendo que tanto la intención de los redactores de la Constitución, como un estudio de los principios básicos que la sostienen llevan a entender que "no se ha otorgado al Congreso un poder para negar la incorporación a un candidato electo, basándose en valoraciones materiales como la falta de idoneidad o la inhabilidad moral" (consid. $7^{\circ}$ de la mayoría).

Estimó que

es claro que la facultad de la Excma. Cámara de Diputados sólo puede referirse a la revisión de la legalidad de los títulos de los diputados electos y la autenticidad de los diplomas, esto es, si fueron regularmente emitidos por la autoridad competente (consid. $6^{\circ}$, id. voto).

En torno al argumento de la idoneidad (art. 16 de la Carta Magna) como condición necesaria para la admisión en la función pública incluso en aquellos supuestos en los que el arribo al cargo sea por vía electoral, estimó que tal exigencia no se

68 Cabe recordar que el actor había sido electo popularmente como diputado nacional por la Provincia de Tucumán, pero al momento de acceder a su banca, la Cámara de Diputados de la Nación le negó su incorporación a dicho Cuerpo en razón de impugnaciones de orden ético realizadas en su contra, por cuanto se le imputaba una suerte de incapacidad moral al atribuírsele la comisión de graves violaciones a los derechos humanos. El frustrado legislador articuló una acción de amparo solicitando la nulidad de la decisión de tal Cámara. El proceso tuvo numerosas vicisitudes y una complicada tramitación que, para llegar al pronunciamiento que referenciamos en el texto, incluyó resoluciones anteriores de la propia Corte Suprema de Justicia de la Nación, por medio de las cuales, respectivamente, revocó primero el criterio de la Cámara Nacional Electoral en punto a que la cuestión era política y por ende no justiciable; y, luego, hizo lo propio en torno a la posición de tal Tribunal electoral que consideraba que el planteo había devenido abstracto al haber sido cubierto el cargo de diputado nacional al que pretendía acceder el accionante. 
discute, sino que de lo que se trata es de precisar quién está facultado para valorar el cumplimiento de ese requisito, concluyendo que en "este caso es el pueblo el que elige a sus representantes quien valora la idoneidad y no la Cámara de Diputados de la Nación, porque el régimen electoral establece justamente el procedimiento adecuado para impugnaciones que permitan a los electores valorar la idoneidad" (consid. $8^{\circ}$, id. voto).

Por último, afrontó facetas sensibles de ciertos sectores temáticos otrora (auto) vedados por reputarlos inmersos en la categoría de political questions. Así, el temperamento que adoptó la mayoría del Tribunal moldea argumental y decisionalmente una respuesta institucional fuerte al asignar un alcance acotado a la facultad de las cámaras legislativas estatuida en la oración que abre el art. 64 de la Ley Fundamental, que reza: "Cada Cámara es juez de las elecciones, derechos y títulos de sus miembros en cuanto a su validez".

\section{h) "Mazzeo"}

Estamos en presencia de un pronunciamiento que, aunque polémico, exuda importancia institucional y un firme mensaje de la Corte Suprema como cabeza de unos de los poderes del Estado, en este caso, al Ejecutivo.

Por mayoría ${ }^{69}$, confirmó la sentencia de la Sala $\mathrm{II}^{\mathrm{a}}$ de la Cámara Nacional de Casación Penal que había reputado inconstitucional el Decreto 1.002/8970 mediante el cual el Poder Ejecutivo Nacional indultó - entre otras personas - a Santiago Omar Riveros en la ex causa 85 de la Cámara Federal de Apelaciones de San Martín. El Máximo Tribunal basó la declaración de inconstitucionalidad del mencionado decreto, en los arts. 18, 31, 75 - inc. 22 -, 99 - inc. $5^{\circ}$ - y 118 de la CN; 1, 8.4 y 25 de la CADH; y 14.7 del PIDCP (consid. 38 del voto que encabeza el decisorio). Naturalmente, la interpretación realizada por la mayoría de la Corte construye un relevante enfoque institucional en torno a la invalidez constitucional de la atribución presidencial de emitir indultos que beneficien a sujetos acusados de cometer delitos de lesa humanidad (ver, por ejemplo, consid. 31 de la mayoría).

Especialmente significativo deviene el consid. 21 de la moción mayoría en el que, mostrando gran permeabilidad hacia los pronunciamientos de la Corte Interamericana de Derechos Humanos, cita el criterio que ésta expusiera en el caso

\footnotetext{
69 Los alineamientos fueron: por la mayoría, votaron los doctores Lorenzetti, Highton de Nolasco, Maqueda y Zaffaroni; en disidencia se expidió el ministro Fayt y en disidencia parcial lo hizo la doctora Argibay.

70 B.O. de 10 de octubre de 1989.
} 
"Almonacid Arellano" "71, de 26 de septiembre de 2006, en los siguientes términos: "La Corte es consciente que los jueces y tribunales internos están sujetos al imperio de la ley y, por ello, están obligados a aplicar las disposiciones vigentes en el ordenamiento jurídico. Pero cuando un Estado ha ratificado un tratado internacional como la Convención Americana, sus jueces, como parte del aparato del Estado, también están sometidos a ella, lo que les obliga a velar porque los efectos de las disposiciones de la Convención no se vean mermados por la aplicación de leyes contrarias a su objeto y fin, y que desde un inicio carecen de efectos jurídicos. En otras palabras, "el Poder Judicial debe ejercer una especie de 'control de convencionalidad' entre las normas jurídicas internas que aplican en los casos concretos y la Convención Americana sobre Derechos Humanos. En esta tarea, el Poder Judicial debe tener en cuenta no solamente el tratado, sino también la interpretación que del mismo ha hecho la Corte Interamericana, intérprete última de la Convención Americana" - remarcado añadido - (párr. 124).

Condensando lo expresado, pone en cabeza de los poderes judiciales de los Estados la obligación de llevar adelante el control de convencionalidad entre las normas jurídicas internas que aplican en los casos concretos y la $\mathrm{CADH}$, tomando en consideración al efecto no sólo la letra de dicho pacto sino la lectura que del mismo ha realizado el Tribunal interamericano que, como se sabe, es el intérprete último de aquél.

En definitiva, entroniza la pauta de interpretación conforme a la CADH como estándar hermenéutico a respetar y resguardar por parte de los órganos jurisdiccionales vernáculos ${ }^{72}$.

\section{i) "Editorial Río Negro S.A."}

Se trata de un fallo que también ostenta valía institucional, resuelto en competencia originaria por la Corte Suprema para preservar la libertad de expresión, reiterar su enorme trascendencia en una nación democrática y republicana y penetrar en el sensible tema del manejo de la publicidad oficial por el Estado.

7 CORTE INTERAMERICANA DE DERECHOS HUMANOS (en lo sucesivo: Corte IDH), "Caso Almonacid Arellano y otros vs. Chile", sentencia sobre excepciones preliminares, fondo, reparaciones y costas, 26 de septiembre de 2006, Serie C, N 154, San José de Costa Rica.

72 Sobre ésta y otras cuestiones conexas, ver BAZÁN, Víctor, por ejemplo, en "El derecho internacional de los derechos humanos y el derecho interno en el escenario argentino: convergencias y desencuentros", E1 Derecho. Serie Especial "Constitucional”, Buenos Aires, 16 de noviembre de 2007, pp. 1/10; o "La interacción del derecho internacional de los derechos humanos y el derecho interno en Argentina", Estudios Constitucionales. Revista semestral del Centro de Estudios Constitucionales, Universidad de Talca, Santiago de Chile, en prensa. 
La demanda (acción de amparo) se sustentaba en la disminución y posterior cesación de publicidad oficial en el Diario Río Negro por parte del gobierno de la Provincia del Neuquén. La accionante atribuía tal actitud gubernamental (catalogada de "discriminatoria") a que en diciembre de 2002 el diario difundió la denuncia que el día 7 de ese mes y ese año un diputado de dicha provincia había efectuado en el sentido de que el vicepresidente primero de la Legislatura local le habría ofrecido un crédito por $\$ 640.000$ de una entidad local a fin de que diera quórum para permitir el tratamiento de las ternas propuestas por el gobernador para cubrir las vacantes judiciales que existían en el Superior Tribunal de Justicia local "con abogados de su confianza".

En este breve repaso no podemos ahondar en la cuestión, por lo que simplemente bosquejaremos de manera esquemática algunos puntos que hacen al patrón elaborado por la mayoría ${ }^{73}$ del Tribunal (consid. 11), que concluyó que: a) medió supresión y reducción sustancial de la publicación oficial al diario demandante; b) no hubo motivos razonables para ello, dejándose sentado que la existencia de los mismos debe ser probada por el Estado; c) se configuró un ejercicio irrazonable de facultades discrecionales; y d) si bien no puede afirmarse la existencia de un derecho de los medios a recibir una determinada cantidad de publicidad oficial, sí existe un derecho contra la asignación arbitraria o la violación indirecta de la libertad de prensa por medios económicos.

Con relación a esto último, la Corte argumentó que el Estado puede dar o no dar publicidad oficial, pero si decide hacerlo debe cumplir dos requisitos constitucionales: a) no puede manipularla, dándola y retirándola a algunos medios en base a criterios discriminatorios; y b) no puede utilizarla como un modo indirecto de afectar la libertad de expresión (id. consid.).

Por lo demás, confirmó que es un deber de los tribunales proteger los medios para que exista un debate plural sobre los asuntos públicos, lo que constituye un presupuesto esencial para el gobierno democrático (consid. 10 de la moción mayoritaria). Asimismo, se remitió a ciertas pautas sentadas por la Corte Interamericana de Derechos Humanos en la OC-5/85 sobre "La colegiación obligatoria de periodistas"74 y en las sentencias recaídas en los casos "La Última Tentación de Cristo [Olmedo Bustos y otros] c/ Chile"75 (5 de febrero de 2001), "Ivcher

\footnotetext{
73 Conformaron la mayoría los doctores Lorenzetti, Highton de Nolasco y Zaffaroni; votando concurrentemente con ellos el ministro Fayt. Por su parte, las disidencias correspondieron en forma individual al doctor Maqueda y conjunta a los ministros Petracchi y Argibay.

74 Corte IDH, OC-5/85, de 13 de noviembre de 1985, "La colegiación obligatoria de periodistas [arts. 13 y 29 Convención Americana sobre Derechos Humanos]”, Serie A: Fallos y Opiniones, $\mathrm{N}^{\circ}$ 5, Secretaría de la Corte, San José de Costa Rica, 1985, específicamente el párr. 69.

75 Corte IDH, Serie C, No 73, párr. 65.
} 
Bronstein c/ Perú"”6 (6 de febrero de 2001) y "Herrera Ulloa c/ Costa Rica"77 (2 de julio de 2004), para concluir reafirmando que la libertad de expresión tiene una dimensión individual y otra social, y que dicha libertad requiere, por un lado, que nadie sea arbitrariamente menoscabado o impedido de manifestar su propio pensamiento y representa, por tanto, un derecho de cada individuo; pero implica también, por otro lado, un derecho colectivo a recibir cualquier información y a conocer la expresión del pensamiento ajeno (id. consid.).

En síntesis, admitió la demanda condenando a la Provincia del Neuquén a que las futuras publicaciones sean adjudicadas con un criterio compatible con las razones expuestas; no obstante lo cual, entendió que las modalidades de ejecución deberían diferir necesariamente de las usuales, por lo que en función de tales condiciones, requirió a la demandada la presentación en un plazo de treinta días de un esquema de distribución de publicidad, respetuoso de los términos y principios que informan la decisión que el Tribunal adoptó.

Con alguna proximidad con "Badaro I" (y luego "Badaro II"), se hace mutatis mutandi perceptible aquí una suerte de mecanismo de doble pronunciamiento, es decir, de sentencias que provisionalmente llamaremos "sucesivas", y que en una aproximación descriptiva superficial de su funcionamiento podría presentarse de la siguiente manera: la primera resolución constata la existencia de la omisión, la declara y formula el encargo o la exhortación al órgano omitente concernido; y la segunda o posterior se emite para resolver la pretensión central contenida en el caso concreto, una vez dictada la norma faltante o el acto preterido, o transcurrido el plazo expreso fijado jurisdiccionalmente o un lapso razonable (si no se hubiese establecido un parámetro temporal determinado) sin que la autoridad competente los hubiese emanado.

\section{B) Decisiones en torno a la determinación de su competencia originaria}

Otra línea jurisprudencial que exhibe el Tribunal radica en la formulación de un estándar restrictivo para determinar su competencia originaria. Esta señal despunta en los precedentes que enunciaremos seguidamente.

\footnotetext{
76 Corte IDH, Serie C, $\mathrm{N}^{\circ} 74$, párr. 149.

77 Corte IDH, Serie C, N 107, párr. 108.
} 


\section{a) Una versión reducida del concepto de "causa civil"}

Se hace perceptible al determinar su competencia originaria por razón de la distinta vecindad o de extranjería, cuyo contorno queda limitado a aquellos litigios regidos exclusivamente por normas y principios de derecho privado, tanto en lo que concierne a la relación jurídica de que se trata como al examen sobre la concurrencia de cada uno de los presupuestos de la responsabilidad patrimonial ventilada y, en su caso, a la determinación y valuación del daño resarcible.

La premisa toma cuerpo por ejemplo en: "Barreto, Alberto D. y otra c/ Buenos Aires, Provincia de y otro s/ daños y perjuicios" ${ }^{\text {"78 }}$, de 21 de marzo de 2006, en el que el Tribunal abandona la generalizada calificación del concepto de "causa civil" que venía aplicando desde el precedente "De Gandia, Beatriz I. c/ Buenos Aires, Provincia de" ${ }^{\text {"79 }}$, de 6 de octubre de 1992. Pasa entonces a fundar su incompetencia para entender en forma originaria en la demanda interpuesta contra una provincia por un vecino domiciliado en otra, a fin de reclamar una indemnización por los daños y perjuicios derivados del accionar irregular imputado a un dependiente de la provincia demandada, ya que dicho litigio no reviste el carácter de "causa civil" en los términos del art. 24 , inc. $1^{\circ}$, del Decreto-Ley $1.285 / 58^{80}$, puesto que se encuentran excluidos de tal concepto los supuestos en los que, pese a reclamarse indemnizaciones de naturaleza civil, se requiere para su solución la aplicación de normas de derecho público provincial o el examen de actos administrativos, legislativos o judiciales de las provincias (consid. $8^{\circ}$ ). Ello así -añade- porque el art. 122 de la $\mathrm{CN}$ veda a la Corte juzgar sobre el funcionamiento de las instituciones locales, so pena de producirse una inadmisible intervención federal en el ámbito del derecho público no delegado (consid. 15).

78 Causa 'B.2303.XL'. El fallo exhibe el voto coincidente de los ministros Petracchi, Highton de Nolasco, Maqueda, Zaffaroni, Lorenzetti y Argibay.

79 Fallos, 315:2309. Los posicionamientos de los votantes de la Corte en su integración de entonces fueron los siguientes: la mayoría quedó compuesta por los ministros Cavagna Martínez, Belluscio, Petracchi, Boggiano y Nazareno; mientras que en disidencia conjunta se expidieron los doctores Levene (h.), Fayt y Barra. El estándar elaborado en "De Gandia" indicaba que a los efectos de la competencia originaria de la Corte Suprema, en los casos en que una provincia era parte, cuando la acción se apoyaba en normas de derecho común y se perseguía la indemnización de los daños derivados de la presunta falta de servicio de un órgano del Poder Judicial de la provincia demandada, correspondía atribuirle carácter civil al pleito. Aclaraba además que, aun cuando para resolver la materia civil de la causa resultara necesario enjuiciar de modo incidental o previo cuestiones de derecho público local, la consideración de estas cuestiones no tenía por fin revisar actos locales, sino apreciar su incidencia en la solución de la causa civil. 
En sintonía con la impronta de "Barreto" se ubican por ejemplo las causas ${ }^{81}$ "Contreras, Carlos Walter c/ Buenos Aires, Provincia de s/ daños y perjuicios" de 18 de abril de 2006, en el que se excluyó la competencia originaria de la Corte en las causas en que se pretende imputar responsabilidad patrimonial a una provincia por los daños y perjuicios sufridos por la actuación u omisión de los órganos estatales en el ejercicio imperativo de sus funciones administrativas, legislativas o jurisdiccionales, en tanto se trata de materia cuya regulación corresponde al campo del derecho público local y de resorte exclusivo de los gobiernos locales, de acuerdo con lo establecido en los arts. 121 y ccds. de la CN (consid. 30); y "Zulema Galfetti de Chalbaud e Hijos Sociedad de Hecho c/ Santa Fe, Provincia de s/ daños y perjuicios" $"$, de 9 de mayo de 2006, proceso en el que la incompetencia originaria se declaró en razón de que la demanda perseguía una indemnización por al accionar irregular en que habría incurrido la provincia accionada al realizar deficientemente una obra pública que produjo efectos perjudiciales en un inmueble de propiedad de la actora, por lo que se trataba de un daño atribuido a la actuación de la provincia como poder público, en ejercicio de funciones estatales que le son propias, materia en cuya regulación - destacó el Máximo Tribunal- conserva una soberanía absoluta que ejerce con arreglo al derecho público local (consid. $5^{\circ}$ ).

\section{b) Una pauta competencial particular en un caso vinculado a la protección del ambiente}

El criterio en cuestión fue adoptado en el pronunciamiento inicial recaído en una conocida causa: "Mendoza, Beatriz S. y otros c/ Estado Nacional y otros" que para poder distinguirla de otras posteriores podría identificarse gráficamente como "Mendoza I". Esta resolución se dictó el 20 de junio de 2006 en el marco de un proceso que gira en torno a la contaminación ambiental de la Cuenca MatanzaRiachuelo y, como adelantábamos, generó varios pronunciamientos ulteriores sobre contingencias procesales puntuales ${ }^{85}$.

81 Al igual que "Barreto", los dos fallos que se nombrarán en el texto llevan las firmas concordantes de los doctores Petracchi, Highton de Nolasco, Maqueda, Zaffaroni, Lorenzetti y Argibay.

82 Causa 'C.4500.XLI'.

83 Causa 'Z.110.XL'.

84 Causa 'M.1569.XL'. Formaron la mayoría del Tribunal los ministros Petracchi, Highton de Nolasco, Maqueda, Lorenzetti y Argibay. A su tiempo, por su voto se expidió el doctor Fayt.

85 Con posterioridad al del 20 de junio de 2006 se dictaron otros resolutorios que conforman la saga "Mendoza", de acuerdo con el detalle que sigue: de 24 de agosto de 2006, en el que la Corte admitió que el Defensor del Pueblo de la Nación actúe como tercero en el proceso aunque rechazó la pretensión de aquél en punto a que se ampliara la acción respecto de varios municipios bonaerenses; de 30 de agosto de 2006, en el que frente a la presentación como terceros 
En ella se declaró la incompetencia originaria del Tribunal en razón de la distinta vecindad o de extranjería - art. 117 de la $\mathrm{CN}$ - frente a reclamos resarcitorios dirigidos contra la Nación, un Estado Provincial, la Ciudad Autónoma de Buenos Aires y ciertas empresas, por lesión de bienes individuales como consecuencia indirecta de la agresión al ambiente - en el caso, debido al vertido de residuos tóxicos y peligrosos en cursos de la mencionada cuenca -, al no verificarse el recaudo de "causa civil" exigido por el señalado art. 24 , inc. $1^{\circ}$, del Decreto-Ley $1.285 / 58$.

Aunque en paralelo, habilitó aquella modalidad competencial originaria en relación con la pretensión tendiente a recomponer el ambiente frente a la degradación o contaminación de sus recursos y resarcir un daño de incidencia colectiva - a causa del vertido de dicho tipo de residuos en el curso de la aludida cuenca - frente al carácter federal de la materia en debate - art. 7 de la Ley 25.675 (Ley General del Ambiente) ${ }^{86}$-, al haberse demandado conjuntamente, entre otros sujetos, a la Nación y a un Estado Provincial.

O sea, por una parte, declaró su incompetencia originaria para conocer de la demanda por el resarcimiento de los daños y perjuicios individuales y, por la otra, fijó su competencia originaria en relación con las pretensiones concernientes a la prevención, la recomposición y el resarcimiento del daño colectivo.

Ya en una resolución posterior en el mismo caso, de 22 de agosto de 2007 (que ilustrativamente podríamos denominar "Mendoza VI"), fijó una serie de reglas que debían observarse en su tramitación (proceso colectivo), de excepcional naturaleza, cuyo objeto procesal es la tutela del bien colectivo (contaminación del Río MatanzaRiachuelo), teniendo como prioridad absoluta la prevención y la recomposición del daño. La fijación de dichas pautas se sustentaba, en palabras de la Corte, en la necesidad de encauzar su trámite mediante un procedimiento útil y eficiente que

de varias asociaciones y fundaciones (art. 30 de la Ley 25.675) que solicitaron se condene al Estado Nacional, a la Provincia de Buenos Aires y al Gobierno de la Ciudad de Buenos Aires y a varias empresas privadas, para que lleven a cabo acciones necesarias para el inmediato cese de la actividad contaminante y la recomposición del daño ambiental colectivo, el Tribunal admitió la participación de cuatro entidades cuyos objetos están relacionados con la protección del medio ambiente, y la rechazó respecto de las restantes; de 23 de febrero de 2007, por el que se ordena la intervención de la Universidad de Buenos Aires a los efectos de que intervenga como perito en la causa; de 20 de marzo de 2007, en el que admite la participación de la asociación de derechos humanos que solicitó ser tenida por tercero y rechazó la petición de varias personas que son actoras en otra causa en la cual impetraron una medida cautelar innovativa y autónoma ante la contaminación que padecen, determinando además el Tribunal que en lo sucesivo serían rechazadas todas las presentaciones por las cuales pretendan incorporarse terceros al proceso, al estar ya suficientemente representada la condición de afectados y/o interesados en cuanto al daño colectivo; y de 22 de agosto de 2007, a la que más adelante nos referiremos en el texto.

86 B.O. de 28 de noviembre de 2002. 
no frustrara ni distorsionara los ingentes intereses comprometidos ni el adecuado y oportuno ejercicio por el Tribunal de su jurisdicción constitucional.

\section{Algunos importantes acuerdos del Tribunal}

Entre las acordadas que de una u otra manera exhiben aspectos de una posición convergente del Tribunal con las líneas subyacentes en los fallos referenciados en el apartado anterior, pueden incluirse las que a continuación mencionaremos.

\section{A) $\mathrm{N}^{\circ} 28 / 04$}

En este acuerdo $^{87}$, de 14 de julio de 2004, reglamentó -por mayoría ${ }^{88}$ - la intervención de "amigos del Tribunal"" (amicus curiae) en procesos judiciales correspondientes a su competencia originaria o apelada en los que se debatan asuntos de trascendencia colectiva o interés general, sin contar con una ley genérica que implementara la figura en cuestión.

Entre otros fundamentos sobre el particular, la posición mayoritaria precisó que la actuación de amici encuentra sustento en el sistema interamericano al cual se ha asignado alcurnia constitucional (art. 75, inc. 22, de la $\mathrm{CN}$ ), pues ha sido objeto de regulación en el Reglamento de la Corte Interamericana (art. 62.3) y la figura ha sido

87 Para un análisis de la aludida acordada, ver BAZÁN, Víctor, "El amicus curiae en clave de derecho comparado y su reciente impulso en el derecho argentino", Cuestiones constitucionales. Revista Mexicana de Derecho Constitucional, $N^{\circ}$ 12, enero-junio 2005, México, D.F.: Instituto de Investigaciones Jurídicas, Universidad Nacional Autónoma de México, pp. $29 / 71$.

88 La acordada en cuestión contó con la rúbrica aprobatoria de los ministros Petracchi, Boggiano, Maqueda, Zaffaroni y Highton de Nolasco, y las disidencias de los doctores Belluscio, Fayt y Vázquez.

89 Venimos bregando desde hace tiempo por la instauración de la figura, razón por la que en su momento nos expedimos laudatoriamente cuando la Corte Suprema se animó a adoptarla aun sin ley genérica en la materia. También saludamos con beneplácito que se hayan plegado a tal temperamento otros importantes tribunales de los ámbitos provincial, por ejemplo, la Suprema Corte de Justicia de Mendoza, cuya Sala Primera admitió la figura por vez primera en la causa No 83.665: "Curel, Gastón Oscar y ots. en J’30.554/114.678, Mancilla Cuello, Enrique Ariel y ots. c/ Municipalidad de la Ciudad de Mendoza p/ Ac. de Amp. s/ Inc.", resuelta el 3 de febrero de 2006 (una breve noticia sobre la misma puede consultarse en BAZÁN, Víctor, "El amicus curiae y su debut en la jurisprudencia de la Sala Primera de la Suprema Corte de Justicia de Mendoza”, La Ley Gran Cuyo, Año 11, N 6, Mendoza, julio 2006, pp. 736/738); y nacional, refiriéndonos en este caso a la Cámara Nacional Electoral - autoridad superior en materia electoral de acuerdo con el art. 5 de la Ley 19.108 (B.O. de 12 de julio de 1971), modificada por Ley 19.277 (B.O. de 7 de octubre de 1971)-, que ha reglamentado recientemente el instituto por medio de la Acordada Extraordinaria No 85, de 19 de julio de 2007. 
expresamente autorizada por la Comisión Interamericana con sustento en los arts. 44 y 48 de la CADH (ver, el consid. $2^{\circ}$, parte in fine, del acuerdo).

Siempre empleado dentro de carriles razonables para evitar que perturbe o entorpezca la normal marcha de los pleitos o desnaturalice los fines para el que fue concebido, el instituto examinado puede constituir una herramienta válida para fortalecer la cotización cualitativa del debate judicial y aportar ingredientes para su democratización, al ampliarse los criterios de participación en causas en que se ventilen asuntos de entidad institucional, interés público o que contengan cuestiones jurídica y/o axiológicamente controvertidas o dilemáticas en los procesos hermenéuticos que puedan conducir a la plasmación de un precedente constitucional.

Por último, es de destacar que si la mayoría de los Estados latinoamericanos ha aceptado la jurisdicción contenciosa de la Corte Interamericana de Derechos Humanos, si además ante ésta existe la posibilidad de comparecer en calidad de amicus curiae y si llegar con un caso ante la misma supone el agotamiento previo de los recursos internos del Estado demandado, requisito éste concedido en interés del propio Estado, resulta entonces absurdo - como enfatizan ABREGú y COURTIS ${ }^{90}$ prohibir a instituciones o grupos interesados presentarse en carácter de amicus ante los tribunales locales (oportunidad frente a la que el Estado tiene posibilidades de remediar la alegada violación) y conceder esa posibilidad después, cuando el Estado ya ha sido demandado ante la Corte por la imputación de los mismos hechos. Por lo demás, siendo la instancia interamericana coadyuvante o complementaria de la que proporciona el derecho local, es razonable ofrecer a los grupos o instituciones interesados en articular opiniones fundadas sobre el tema en cuestión la misma posibilidad de participación procesal en sede interna que la que tienen en el ámbito internacional, adelantando ante los tribunales locales los argumentos que eventualmente serán considerados por el Tribunal con sede en Costa Rica.

\section{B) $\mathrm{N}^{\circ} 17 / 05$}

Por medio de esta acordada ${ }^{91}$, de 2 de agosto de 2005, dispuso asignar a su Secretaría Judicial $N^{\circ} 6$ el trámite de las causas concernientes a su competencia apelada, en las cuales se ponga en juego, de manera directa, inmediata y trascendente, la interpretación y aplicación del derecho de los derechos humanos.

\footnotetext{
90 ABREGÚ, Martín y COURTIS, Christian, "Perspectivas y posibilidades del amicus curiae en el derecho argentino", en La aplicación de los tratados sobre derechos humanos por los tribunales locales, cit. en nota 31, pp. 392/393.

91 Suscripta por los doctores Petracchi, Belluscio, Maqueda, Zaffaroni, Highton de Nolasco, Lorenzetti y Argibay.
} 
Además del tramo dispositivo, resultan dignos de subrayar algunos segmentos de su fundamentación, por ejemplo, aquellos en los que -entre otras apreciaciones - califica de "hito mayúsculo" al reconocimiento de jerarquía constitucional de los mayores instrumentos internacionales de derechos humanos (párr. $3^{\circ}$ de los considerandos), lo que - sigue exponiendo el Tribuna l- dio lugar a una singular recepción en la cumbre del ordenamiento jurídico argentino al derecho internacional de los derechos humanos, produciendo tres importantes consecuencias, al menos: "[e]n primer lugar, introdujo nuevos derechos o imprimió nuevos contenidos a los ya existentes. En segundo término, puso en cabeza del Estado obligaciones relativas al respeto, protección y realización de los derechos humanos de toda persona sometida a su jurisdicción. Finalmente, emplazó a nuestro país en sistemas internacionales de control del cumplimiento de los aludidos compromisos" (párr. $4^{\circ}$ de los considerandos).

$\mathrm{Al}$ respecto, puntualizó que la prescindencia de las normas internacionales por los órganos estatales - incluidos los de carácter jurisdiccional - puede originar responsabilidad internacional del Estado argentino, por lo que juzgó aconsejable que en los casos de competencia apelada en los cuales se ponga en juego, de la manera indicada precedentemente, la interpretación y la aplicación del derecho de los derechos humanos, tramiten por una secretaría judicial especializada en la materia (párr. $6^{\circ}$ de los considerandos).

El anclaje argumental que da base a la acordada es elocuente y la finalidad de ésta excede ampliamente el mero cumplimiento de una función instrumental o de ordenamiento administrativo. Por el contrario, se presenta como una muestra evidente más de la firme posición institucional que adopta la Corte al reforzar axiológica y jurídicamente su compromiso, como Poder del Estado, frente al derecho de los derechos humanos en las causas que arriben a sus estrados.

\section{C) $\mathbf{N}^{\circ} 04 / 07$}

El acuerdo en cuestión (que ha generado mucha polémica), de 16 de marzo de 2007, reglamenta los escritos de interposición del recurso extraordinario y del recurso de queja por denegación de aquél, fundándose en que, con particular referencia a los libelos de que se trata, "justifica la sistematización que se lleva a cabo como un provechoso instrumento para permitir a los justiciables el fiel cumplimiento de los requisitos que, como regla, condicionan el ejercicio de la jurisdicción constitucional que este Tribunal ha considerado como eminente" (énfasis añadido). 


\section{D) $\mathbf{N}^{\circ} 12 / 07$}

Fue dictada en fecha 3 de julio de $2007^{92}$. Por su intermedio se crea en el ámbito de la Corte, y con dependencia directa de su Presidente, la Oficina de Fortalecimiento Institucional, con el objeto de contribuir a profundizar la transparencia de los trámites judiciales y permitir un adecuado control por parte de todos a quienes concierne e interesa el mejor funcionamiento del Poder Judicial; de facilitar el acceso eficiente a la información jurídica procurando una activa participación de aquellos sectores que, por su rol institucional, tienen mayor responsabilidad en la administración de justicia; y, entre otras cosas y en suma, de garantizar a toda la población, en condiciones de igualdad, el efectivo acceso a la jurisdicción y a un pronunciamiento oportuno y eficaz sobre las cuestiones que se traen a conocimiento de los jueces.

En definitiva, el propósito primordial que persigue el acuerdo aquí colacionado, consiste en la indispensabilidad de adoptar nuevas medidas que permitan profundizar el proceso de fortalecimiento del Poder Judicial como condición esencial para garantizar el imperio del Estado de Derecho y el funcionamiento armónico de las instituciones de la República.

\section{E) $\mathrm{N}^{\circ} 14 / 07$}

Sustentándose en que venía tomando conocimiento de diversas circunstancias de naturaleza administrativa y funcional, que obstaculizan o dificultan la adecuada tramitación de gran cantidad de causas penales concernientes a la presunta violación de derechos humanos en hechos ocurridos antes del 10 de diciembre de $1983^{93}$, radicadas ante tribunales federales de distinta instancia en todo el territorio de la República Argentina; el 11 de julio de $2007^{94}$ emitió tal acordada por cuya virtud la Corte crea en su ámbito una Unidad de Asistencia y Seguimiento de las Causas Penales en las que se investiga la desaparición forzada de personas, acaecidas antes del 10 de diciembre de 1983, unidad que operará transitoriamente hasta concluir con la misión encomendada.

\footnotetext{
92 Firmada por los ministros Lorenzetti, Highton de Nolasco, Fayt, Maqueda y Argibay.

93 Fecha histórica en Argentina por el renacimiento democrático luego del último gobierno de facto comenzado en marzo de 1976.

94 Suscripta por los ministros Lorenzetti, Highton de Nolasco, Petracchi, Maqueda, Zaffaroni y Argibay.
} 


\section{F) $\mathbf{N}^{\circ} 30 / 07$}

Dictada el 5 de noviembre de 2007, y firmada por todos sus integrantes ${ }^{95}$, el Tribunal dio un importante paso institucional al implementar el régimen de audiencias públicas.

Desde nuestro punto de vista, y como hemos sostenido en reiteradas ocasiones, tanto las audiencias de carácter público en la Corte Suprema como la intervención ante ésta de amici curiae, constituyen instrumentos útiles para ensanchar el horizonte de participación popular en causas que excedan el interés propio y específico de las partes directamente involucradas en la contienda y, paralelamente, para transparentar el debate judicial.

Entre otros fundamentos, la Corte manifestó que la participación ciudadana en dichas audiencias y la difusión pública del modo en que conoce de los asuntos en que, con carácter primordial, ha de ejercer la jurisdicción más eminente que le confiere la Constitución Nacional, permitirá poner a prueba directamente ante los ojos del país la eficacia y objetividad de la administración de justicia que el Tribunal realiza ${ }^{96}$.

Por último, puede acotarse que el acuerdo de marras prefigura tres clases de audiencias públicas: a) informativa, para escuchar e interrogar a las partes sobre aspectos del caso por decidir; b) conciliatoria, que tendrá por objeto instar a las partes en la búsqueda de soluciones no adversariales; y c) ordenatoria, en orden a tomar las medidas que permitan encauzar el procedimiento a fin de mejorar la tramitación de la causa.

\section{Un intento por decodificar y relacionar determinados mensajes y señales que emite el Tribunal}

\section{Insumos conceptuales}

Para comprender la lógica de algunas cuestiones adelantadas y de otras que se verterán infra, fundamentalmente en torno al recurso a las modalidades sentenciales "atípicas", a la modulación de los efectos del control de constitucionalidad, al trazado de vinculaciones dialógicas con otros poderes estatales y a la corrección de las

\footnotetext{
95 O sea, rubricada por los doctores Lorenzetti, Highton de Nolasco, Petracchi, Fayt, Maqueda, Zaffaroni y Argibay.

96 El párrafo transcripto corresponde al dictamen del Procurador General de la Nación en la causa "Penjerek", al que remite la sentencia de la Corte de 14 de noviembre de 1963 (Fallos, 257:134).
} 
omisiones inconstitucionales (asuntos que, por lo común, corresponden a tribunales o cortes constitucionales o a salas constitucionales incardinadas en cortes supremas de justicia), es necesario efectuar siquiera una breve aproximación explicativa.

\section{A) En torno al paradigma del "legislador negativo" y las sentencias "atípicas o intermedias"}

Como advierte Garrorena Morales, el simplificado esquema que Kelsen inicialmente manejara, reducido a distinguir dos únicos tipos de sentencias (estimatorias y desestimatorias), y abocado a considerar al tribunal constitucional como un mero legislador negativo cuyas resoluciones no podían conllevar más creación de Derecho que la escueta anulación de la ley, ha dejado de ser útil como respuesta a las cada vez más complejas operaciones en las que se ven implicados los tribunales constitucionales ${ }^{97}$.

Al quedar atrás como alternativa exclusiva el tándem constitucionalidad-inconstitucionalidad, se avanza hacia posiciones teñidas de cierto activismo para modelar diversas formulaciones sentenciales que reflejan la función normativa que aquéllos pueden llevar a cabo en los contextos legal y constitucional mediante su labor hermenéutica ${ }^{98}$.

Los retos y exigencias que se ciernen sobre los órganos de cierre de las respectivas jurisdicciones constitucionales obligan a superar los esquemas y moldes kelsenianos exigiéndoles - como mutatis mutandi refiere TAJADURA TEJADA - llegar hasta las últimas fronteras de la Constitución normativa para consolidarse como verdadero Tribunal de los "ciudadanos" ${ }^{99}$ o, en visión más abarcativa, de los "habitantes".

En ese escenario, esencialmente en Europa (v.gr., en los Tribunales Constitucionales de Alemania, Austria, España y la Corte Constitucional de Italia), aunque con irradiaciones hacia nuestro continente (v.gr., en la Corte Constitucional de Colombia, los Tribunales Constitucionales de Perú, Chile y Bolivia y las Salas

97 GARRORENA MORALES, Ángel, "Opacidad y desestimación de la inconstitucionalidad en el fallo de las sentencias interpretativas", La Democracia Constitucional. Estudios en homenaje al Profesor Francisco Rubio Llorente, Congreso de los Diputados, Tribunal Constitucional, Madrid: Universidad Complutense de Madrid, Fundación Ortega y Gasset, Centro de Estudios Políticos y Constitucionales, 2002, pp. 1844/1845.

98 Ver, por todos, GONZÁLEZ BEILFUSS, Markus, Tribunal Constitucional y reparación de la discriminación normativa, Madrid: Centro de Estudios Políticos y Constitucionales, 2000, pp. $12 / 13$.

99 TAJADURA TEJADA, Javier, "Retos y desafíos de la justicia constitucional en los umbrales del siglo XXI", en AA.VV., Visión iberoamericana del tema constitucional, cit. en nota 14, pp. 438/439. 
Constitucionales de la Corte Suprema de Justicia de Costa Rica y del Tribunal Supremo de Justicia de Venezuela), fue plasmándose la construcción jurisprudencial de "sentencias atípicas o intermedias" que reconocen una raíz primordialmente pragmática.

En torno a estas modalidades sentenciales existen tantas clasificaciones como autores se embarcan en intentos taxonómicos a su respecto. Primariamente puede decirse que la problemática de la interpretación conforme a la Constitución (Verfassungskonforme Auslegung de la doctrina alemana) mucho tiene que ver con el surgimiento y la proliferación de estas variantes decisorias. Siguiendo a Groppi, la idea se inscribe en el marco de la “'minimización’ del impacto de las decisiones de inconstitucionalidad sobre el sistema, a fin de evitar vacíos y de buscar un equilibrio entre la necesidad de eliminar normas inconstitucionales y la de no crear lagunas o discontinuidades que pondrían en duda el carácter de ordenamiento jurídico (...). Con las sentencias interpretativas el juez constitucional hace propia una de las interpretaciones posibles de la disposición censurada, escogiendo la que es conforme (sentencia interpretativa de rechazo) o la contraria (sentencia interpretativa estimatoria) a la Constitución" ${ }^{100}$.

De su lado, las "sentencias interpretativas" están estrechamente vinculadas a la interpretación conforme y parten del presupuesto de la distinción entre disposición y norma, o entre el enunciado normativo y la norma que, por medio de la interpretación constitucional, se desprende del mismo. Ligada a tal faceta de la cuestión, una de las numerosas aproximaciones que se han ensayado sobre las sentencias interpretativas - en este caso correspondiente a RUBIo LLORENTE - las entiende como aquellas que emiten un pronunciamiento, no sobre el enunciado de la ley sino de una norma que de él puede deducirse mediante los medios habituales de interpretación ${ }^{101}$.

Delineados sumariamente algunos lineamientos sobre el particular, sólo mencionaremos ilustrativamente que, dentro de la categorización de las "interpretativas", existen por ejemplo las sentencias "manipulativas"102, que a su vez, pueden

$\overline{100}$ GROPPI, Tania, “¿Hacia una justicia constitucional 'dúctil’? Tendencias recientes de las relaciones entre Corte Constitucional y jueces comunes en la experiencia italiana", en FERRER MAC-GREGOR, Eduardo (coordinador), Derecho Procesal Constitucional, T ${ }^{\circ}$ I, $4^{a}$ ed., Colegio de Secretarios de la Suprema Corte de Justicia de la Nación, A.C., México, D.F.: Edit. Porrúa, 2003, p. 355.

101 RUBIO LLORENTE, Francisco, en el capítulo "La jurisdicción constitucional como forma de creación del derecho" de su libro La forma del poder. Estudios sobre la Constitución, $2^{\text {a }}$ ed., Madrid: Centro de Estudios Constitucionales, 1997, p. 484.

${ }^{102}$ Mutatis mutandi, TORRES DEL MORAL ha sostenido gráficamente: "De cara a la vida deseablemente estable de una Constitución, no hay más apuesta posible que la reformista. Sean bienvenidas las interpretaciones imaginativas, las sentencias manipulativas y aun las mutaciones disimuladas. Al final, toda Constitución es fruto de su tiempo y el transcurso de éste termi- 
ser "sustitutivas", "reductoras" o "aditivas". Las primeras sustituyen una interpretación plausible, pero inconstitucional, del precepto legal impugnado, por otra que claramente no se deduce del mismo, pero que resulta acorde con la Constitución; las "reductoras" suponen precisamente una interpretación restrictiva del ámbito de aplicación del precepto legal impugnado para conformarlo a la Constitución, como producto de lo cual, y luego de la tarea interpretativa, la regla deja de ser aplicable en uno o varios de los supuestos comprendidos en abstracto por el enunciado legal; y las "aditivas", que implican la aceptación de la inconstitucionalidad por omisión (vid. infra), consisten en una interpretación extensiva del radio de acción del precepto legal objetado, para conformarlo a la Constitución, de resultas de lo cual y tras la interpretación, la regla es aplicable a más supuestos de los comprendidos en abstracto por el enunciado legal ${ }^{103}$.

Dentro de este recorrido meramente enunciativo, no podríamos dejar de incluir, las sentencias que modulan sus efectos, y que en general, suponen una interacción entre el tribunal o corte constitucionales con el Poder Legislativo y/o con la magistratura ordinaria (de allí que también se las denomine "sentencias bilaterales" o "multilaterales" si involucran a otro u otros órganos públicos además del Congreso o Parlamento). Entre ellas podemos citar las declaraciones de mera incompatibilidad o de inconstitucionalidad sin nulidad o de inconstitucionalidad simple; las sentencias apelatorias; las que declaran que la ley "todavía no es inconstitucional"; el retraso de los efectos de la sentencia para dar tiempo a la intervención del legislador; las sentencias exhortativas y las "sentencias aditivas de principio" o las "sentencias-delegación" 104.

na desvelando sus carencias, sus defectos técnicos e incluso sus errores políticos. La necesidad de su reforma se hace entonces evidente" - remarcado añadido- (TORRES DEL MORAL, Antonio, "El instituto de la rigidez como garantía de la Constitución", en BAZÁN, Víctor [coordinador], Defensa de la Constitución. Garantismo y controles. Libro en reconocimiento al Doctor Germán J. Bidart Campos, Buenos Aires: Ediar, 2003, pp. 432/433).

103 Cfr. GASCÓN ABELLÁN, Marina, Voz: "Interpretación conforme (con la Constitución)", en Diccionario de Derecho Constitucional, cit. en nota 8, p. 318.

104 Ver al respecto, mutatis mutandi, DÍAZ REVorio, Francisco J., "El control de constitucionalidad de las omisiones legislativas relativas en el derecho comparado europeo", Revista Española de Derecho Constitucional, N 61, Año 21, enero-abril 2001, Madrid: Centro de Estudios Políticos y Constitucionales, pp. 85/86. 


\section{B)Sobre la inconstitucionalidad por omisión ${ }^{105}$ y los lazos dialógicos de la magistratura constitucional u ordinaria con otros poderes estatales}

Obviamente, la Constitución puede ser vulnerada no sólo por acción, sino, también, por omisión; concretamente en este último caso, cuando no se actúa a pesar de la expresa previsión constitucional dirigida a que se lo haga o cuando se regula de modo deficiente plasmando una reglamentación insuficiente o discriminatoria al no dotar a algunos de lo que, en igualdad de condiciones o circunstancias, acuerda a otros.

El ejercicio del control sobre las omisiones inconstitucionales persigue - inter alia - recomponer el imperio de la Norma Básica, cuya primacía habría quedado momentáneamente bloqueada por la agresión negativa del órgano omitente. En línea con ello, cabe recordar que el control de constitucionalidad como noción jurídica es inseparable de la de Constitución como norma suprema de un ordenamiento jurídico dado ${ }^{106}$.

Como mutatis mutandi constata CARrILlo, en Europa (aunque -agregamos por nuestra parte- con reflejos en el marco latinoamericano), la configuración de la justicia constitucional como mecanismo de defensa de la Constitución, ha supuesto una notable innovación en la función jurídica y política de la Ley Fundamental: desde el punto de vista jurídico, porque no hay duda que la Constitución adquiere progresivamente la condición de norma jurídica exigible ante los poderes públicos y los particulares; y desde la óptica política, porque aquélla ordena el sistema político y los Tribunales Constitucionales se convierten en instrumentos de defensa del ordenamiento constitucional ante el legislador y el resto de los poderes del Estado ${ }^{107}$.

La alusión referencial anterior da pie para reiterar que la discusión en torno a las posibilidades de sustentación jurídico-política del contralor de constitucionalidad sobre las omisiones inconstitucionales representa un capítulo más de la tensión

$\overline{105}$ Sobre el tema, entre otros trabajos de BAZÁN, Víctor, ver "Respuestas normativas y jurisdiccionales frente a las omisiones inconstitucionales: una visión de derecho comparado", en CARBONELL, Miguel (coordinador), En busca de las normas ausentes. Ensayos sobre la inconstitucionalidad por omisión, $2^{\mathrm{a}}$ ed., México, D.F.: Instituto de Investigaciones Jurídicas, Universidad Nacional Autónoma de México, 2007, pp. 75/270.

106 VILLAVERDE MENÉNDEZ, Ignacio, La inconstitucionalidad por omisión, Madrid: McGraw-Hill, 1997, p. 3.

107 CARRILLO, Marc, "La Jurisdicción Constitucional en Europa: las funciones del Tribunal Constitucional Español y las hipotecas del caso chileno", en MORODO, Raúl y DE VEGA, Pedro (directores), Estudios de Teoría del Estado y Derecho Constitucional en honor de Pablo Lucas Verdú, $T^{\circ}$ II, Madrid: Universidad Nacional Autónoma de México (Instituto de Investigaciones Jurídicas) y Servicio de Publicaciones de la Facultad de Derecho de la Universidad Complutense de Madrid, 2000, p. 1472.

Revista Mestrado em Direito, Osasco, ano 10, n. 2, p. 113-169 
constitucionalismo-democracia, judicatura-Congreso o, en otras palabras, de la delicada vinculación entre jurisdicción y legislación ${ }^{108}$.

Las omisiones inconstitucionales del Poder Legislativo, que detienen y mediatizan la normatividad y la supremacía de la Carta Magna, pueden ser - en una simplificación taxonómica extrema ${ }^{109}$-: absolutas o totales, cuando directamente media ausencia de la norma que debería regular una determinada situación jurídica fijada constitucionalmente; y relativas o parciales, cuando el legislador, al emitir la norma para cumplir el mandato constitucional, y en equivalencia de condiciones y circunstancias, favorece a ciertos grupos y, sin fundamento objetivo, deja de lado a otros o concede ventajas a unos que no son dispensadas a otros, es decir que, al legislar, se lesiona el principio de igualdad o se emite una regulación deficiente gestada por una regla incompleta o normativamente insuficiente.

En este ámbito, y particularmente ligadas a las omisiones inconstitucionales relativas o parciales, son las citadas sentencias aditivas las de mayor significación y utilidad en el proceso de control aquéllas.

De una visita relámpago al derecho comparado, y sin intención alguna de exhaustividad, se observa que la problemática de la inconstitucionalidad por omisión ha sido institucionalizada por conducto de las Constituciones Nacionales, por ejemplo, en Portugal y Hungría, en tierras europeas, y en Brasil y Venezuela, ya en dominios latinoamericanos; por la senda legal en Costa Rica, o por conducto de las Constituciones locales en países con estructura federal como Brasil, México y Argentina. Asimismo, fue focalizado e implementado jurisprudencialmente por los Tribunales Constitucionales de Alemania y España y la Corte Constitucional italiana, en Europa; y por la Corte Constitucional de Colombia, los Tribunales Constitucionales del Perú y de Bolivia y la Suprema Corte de Justicia de República Dominicana.

Extrapolando algunas de las precedentes consideraciones al caso argentino, vemos que aquellas relaciones tensionales entre el Poder Judicial y el Congreso deben reconducirse en términos constructivos y, en el contexto específico de la inercia o la mora legislativas anticonstitucionales, la labor jurisdiccional superadora que al respecto acometa la Corte Suprema de Justicia como cabeza del cuerpo judiciario, no debería ser impulsada (ni entendida) en un plano confrontativo o de puja de

\footnotetext{
108 La frase que cierra este tramo del texto: "la delicada vinculación entre jurisdicción y legislación”, es paráfrasis de la apreciación de ZAGREBELSKY, quien alude a "lo delicado de la relación entre jurisdicción y legislación” (ZAGREBELSKY, Gustavo, E1 derecho dúctil. Ley, derechos, justicia, trad. de Marina Gascón, $3^{\text {a }}$ ed., Madrid: Trotta, 1999, p. 152).

109 Para la distinción entre omisiones inconstitucionales absolutas y relativas, ver WESSEL, W., "Die Rechtsprechung des Bundesverfassungsgerichts zur Verfassungsbeschwerde", Deutsches Verwaltungsblatt (DVB1), cuad. 6, 1952, p. 164.
} 
poder, sino desde la vertiente del diálogo y la colaboración comprometidos institucionalmente en la búsqueda de un equilibrio que, sin soslayar la irrenunciable misión del Alto Tribunal de conservar inalterada la vigencia normativa suprema de la Constitución, resguarde la estructura del Estado, la división de poderes, la autoridad democrática del legislador y su libertad de configuración política.

En esa dinámica de articulación es tan aconsejable que la Corte actúe impregnada de un activismo prudente, como que el Congreso asuma la vital importancia de su rol institucional y actúe a la altura de las circunstancias que el Estado Constitucional de Derecho le impone.

\section{Nuestra lectura decodificatoria de la cuestión}

Nutriéndonos de algunos de los insumos conceptuales volcados precedentemente, y contrastándolos con ciertos vestigios que se desprenden de las líneas recorridas por la Corte Suprema en los casos y acuerdos reseñados supra (obviamente adaptados al esquema de jurisdicción constitucional y de control de constitucionalidad y al sistema de división de poderes y reparto de funciones de nuestro país); es hora de efectuar sumarias reflexiones para arriesgar una respuesta al interrogante que planteábamos en el título general de este trabajo.

Ciertamente, es dable observar que el Tribunal ha comenzado a:

recurrir con más frecuencia a variantes "atípicas" de sentencias ("Verbitsky", "Massa", "Rosza", "Editorial Río Negro");

modular temporalmente los efectos del control de constitucionalidad que realiza ("Itzcovich", "Rosza"), dando paso a una interpretación previsora; generar relaciones dialógicas con otros poderes de los Estados Nacional o Provinciales, dirigiéndoles comunicaciones, encargos o exhortaciones (“Badaro I y II”, "Verbitsky”);

avanzar algunos pasos en el territorio de la "inconstitucionalidad por omisión" ("Badaro I y II");

ingresar al examen de ciertos aspectos emparentados con cuestiones otrora reputadas no justiciables - political questions- ("Itzcovich", "Bussi", "Mazzeo");

evitar estratégicamente el contralor de constitucionalidad dado el tiempo transcurrido hasta el momento de pronunciarse en causas de trascendencia institucional y en función de una interpretación previsora de las consecuencias e implicancias que al sistema provocaría ejercer tal ejercicio de fiscalización constitucional - en el marco de la técnica de la "evitación" o avoidance doctrine según el derecho norteamericano - ("Rinaldi"); 
depurar la competencia discernida por ley del Congreso en el ámbito de los recursos ordinarios de apelación ordinaria en materia previsional ("Itzcovich");

diseñar un estándar más exigente para habilitar su competencia originaria ("Barreto", "Mendoza I"), y en el marco de ésta, fijar determinadas pautas para no frustrar el adecuado y oportuno ejercicio de su jurisdicción constitucional ("Mendoza VI");

reivindicar su rol institucional como cabeza de Poder ("Itzcovich", "Bussi”, “Mazzeo", “Rosza”, "Editorial Río Negro”);

abrir canales de participación popular que puedan llevar a una mayor democratización del debate en cuestiones dilemáticas, conflictivas y de envergadura constitucional (a través de las figuras del amicus curiae y de las audiencias de carácter público); e inter alia

reglamentar los escritos de interposición del recurso extraordinario y del recurso de queja por denegación de aquél como instrumento para permitir a los litigantes el fiel cumplimiento de los requisitos que, como regla, condicionan el ejercicio de la jurisdicción constitucional que el Tribunal considera como eminente.

Enfocados individualmente o en interrelación, los factores indicados no son sino señales que -más sostenidamente a partir de su actual composición - emite la Corte para fortalecer su presencia institucional en el esquema republicano de división de funciones; reforzar su papel de intérprete supremo de la Constitución; racionalizar sus fuerzas y recursos para dedicarlos esencialmente al tratamiento de cuestiones constitucionales sustantivas, es decir, que le permitan no entretenerse en asuntos menores, constitucionalmente insustanciales o que la alejen de la meta que cataloga como fundamental en su quehacer: mejorar su funcionamiento concentrando sus decisiones de modo preferente en el responsable ejercicio de su jurisdicción constitucional.

Así, la imagen que proyectan aquellos elementos sugiere que la Corte está inmersa en un proceso para reconfigurarse en los hechos como un tribunal constitucional, o sea, desde el punto de vista material. 


\section{De ciertos desafíos y temas pendientes que la Corte Suprema tiene por delante}

Previo a dar paso al epílogo de este trabajo, relevaremos telegráficamente algunos retos y aspectos pendientes conflictivos que tiene por delante el Tribunal. Razones de brevedad nos impiden abordar exhaustivamente tales tópicos, por lo que sólo nos dedicaremos a enunciarlos someramente.

1. En primer lugar, deberá determinar si continúa con la depuración de su competencia para concentrarse principalmente en cuestiones constitucionales sustanciales, y si hace lo propio en torno a la reducción de los márgenes de viabilidad de las causales de arbitrariedad que habilitan el recurso extraordinario federal, pues sin lugar a dudas aquéllas representan el componente mayoritario del volumen de causas de su jurisdicción apelada.

2. Estrechamente vinculado a las cuestiones referidas precedentemente, MorELLO hace foco en algunos aspectos medulares y por cierto polémicos, indicando que "deberá esclarecerse el emplazamiento cabal del Tribunal. Si vuelve a sus orígenes y a lo clásico y propio (Corte de garantías constitucionales) y se despoja del agregado casacional que traba su desenvolvimiento (el 80\% de lo apelado circula por el corredor de las sentencias arbitrarias)", para pasar a preguntarse si "se crearán Tribunales intermedios regionales para abastecer la revisión de las sentencias tachadas de arbitrariedad" otro tipo de tribunales que no es precisamente pacífico en la doctrina pero en cualquier caso resulta útil para reinstalar el debate sobre qué alternativas institucionales surgirían ante una eventual extirpación del componente casacional de la competencia del Alto Tribunal.

Tangencialmente, aunque con algún punto de toque con el problema bosquejado líneas arriba, cabe recordar que en "Casal"111, y en orden a garantizar el derecho a la doble instancia del condenado en un juicio oral adecuándolo a las exigencias de la CADH (art. 8.2.'h') y el PIDCP (art. 14.5), la Corte Suprema hizo algún movimiento resolviendo que la Cámara Nacional de Casación Penal no será en adelante una instancia extraordinaria sino que actuará como instancia ordinaria, es decir, que deberá realizar una revisión amplia del caso (de acuerdo con el art. 456 del Código Procesal Penal de la Nación), con lo cual no podrá limitarse a examinar sólo cuestiones jurídicas,

\footnotetext{
$\overline{110}$ MORELLO, Augusto M., op. cit., pp. 163/164.

111 Autos "C.1757.XL, 'Casal, Matías Eugenio y otro s/ robo simple en grado de tentativa - causa $n^{\circ} 1.681$ - "', de 20 de septiembre de 2005. La mayoría estuvo compuesta por los doctores Petracchi, Maqueda, Zaffaroni y Lorenzetti. Por su parte, en votos concurrentes se expidieron los ministros Highton de Nolasco, Fayt y Argibay.
} 
sino también los hechos expuestos y las pruebas rendidas en el juicio oral ${ }^{112}$.

3. Por su parte, y en una nómina temática que dista de ser taxativa, tendrá que definir cuestiones complejas como:

los anunciados exámenes de constitucionalidad de la Ley 26.080, que modifica la composición del Consejo de la Magistratura, y de la Ley 26.122 , en torno al siempre ríspido problema de los decretos de necesidad y urgencia;

el rol del proceso de amparo, en función de lo cual por razones de seguridad jurídica y como guía para la compatibilización jurisprudencial de los tribunales inferiores al respecto, debería decantarse por una de las opciones en pugna; esto es, si aquél ofrece una vía subsidiaria o supletoria o si, contrariamente, supone una senda directa o principal. Tal disputa dialéctica, que continúa dividiendo a la doctrina, se reavivó con el proyecto de ley sobre la materia que en 2006 obtuvo "media sanción" en la Cámara de Diputados de la Nación, pasando a la de Senadores para su revisión;

la validez vis-à-vis la Constitución y los instrumentos internacionales sobre derechos humanos con jerarquía constitucional, de la reglamentación de los escritos de interposición del recurso extraordinario y del recurso de queja por denegación de aquél, instrumentada por la citada Acordada $\mathrm{N}^{\circ}$ 04/07; y

es probable que deba asimismo precisar un punto controversial como el de la prescriptibilidad o imprescriptibilidad de los delitos cometidos por miembros de agrupaciones como "Montoneros" que actuaron en la década de los '70 del siglo pasado, para lo que deberá la Corte establecer si tales conductas constituyen o no crímenes de lesa humanidad.

4. De su lado, no parece fútil reiterar la discutible tendencia patentizada en numerosos decisorios del Tribunal, al multiplicarse los fundamentos que los sustentan en proporción directa a los miembros votantes, es decir, a recaer en una fragmentación o atomización argumentales.

En aras de preservar la seguridad jurídica y la predictibilidad de sus decisorios, sería aconsejable que los jueces de la Corte se esforzaran al máximo para lograr ciertos niveles mínimos de consenso, empleando instrumentos argumentativos co-

$\overline{112}$ El consid. 23 del voto mayoritario indica que el aludido precepto procesal penal debe ser leído exegéticamente proporcionando un resultado análogo al de la doctrina y la jurisprudencia alemanas con la teoría de la Leistungsfähigkeit, o sea, que el tribunal de casación debe agotar el esfuerzo por revisar todo lo que pueda revisar, es decir, por agotar la revisión de lo revisable. En otras palabras, el Tribunal interpreta tal norma de acuerdo con la teoría del máximo de rendimiento (consid. 32 de la mayoría), debiendo la tarea revisora ser todo lo extensa que sea posible conforme a las posibilidades y constancias de cada caso particular y sin magnificar las cuestiones reservadas a la inmediación, sólo evitables por imperio de la oralidad conforme a la naturaleza de las cosas (consid. 34 de la moción triunfante). Tal posición fue reiterada poco tiempo después por la Corte en el pronunciamiento producido en el expediente "M.1451. XXXIX, 'Martínez Areco, Ernesto s/ causa № 3792, recurso de casación (interpretación del art. 456, inc. $2^{\circ}$, del Código Procesal Penal de la Nación)”, de 25 de octubre de 2005. 
munes que permitan conocer nítidamente cuál es el criterio unánime o mayoritario concreto del Cuerpo, al menos, en pronunciamientos que sienten doctrina, diriman casos difíciles, aborden cuestiones jurídicas neurálgicas o fijen posición en temas de gravedad o incidencia institucionales.

5. Por último, pero no menos importante, pensamos que otro significativo desafío que sobrevuela a algunos pronunciamientos del Tribunal, sobre todo aquellos de corte activista y/o que involucran a otros poderes del Estado, radica en la necesidad de perfilar instrumentos adecuados que permitan lograr la eficacia de tales decisorios y evitar que ellos se aletarguen en la inocuidad, pues de lo contrario, éstos quizás sean teóricamente ideales pero impracticables en la realidad, con lo cual no se avanzará precisamente en el afianzamiento de la justicia sino que, en el mejor de los casos, sólo se volverá al punto de partida.

\section{Apreciaciones finales y de conjunto}

Como es de suponer, las anotaciones precedentes no agotan todos los aspectos de la delicada cuestión en torno a la cual gira el presente trabajo. Como fuera, del itinerario panorámico emprendido pueden extraerse las siguientes observaciones finales, que vienen a añadirse a otras apreciaciones conclusivas ya intercaladas en otros tramos de esta contribución:

1. El Estado contemporáneo es Estado Constitucional, en cuyo contexto la Constitución ocupa un lugar central en el sistema jurídico (junto a los instrumentos internacionales universales y regionales básicos en materia de derechos humanos con valencia homóloga a la de la Carta Fundamental) y recepta fuerza normativa. Consiguientemente, en el modelo jurídico-político del "neoconstitucionalismo" (o de los "neoconstitucionalismos"), representativo del Estado Constitucional, ha variado el concepto y la magnitud de la Constitución, que ha pasado a impregnar y gobernar el ordenamiento jurídico; se ha modificado el posicionamiento que los órganos de cierre de la jurisdicción constitucional deben asumir frente a ella; se ha tornado evidente que la Constitución es un instrumento "dialéctico", que además de reglas, contiene principios y valores que pueden ser potencialmente conflictivos y que adquieren relevancia como ingredientes necesarios para comprender la estructura y el funcionamiento de un sistema jurídico ${ }^{113}$; se han diversificado las

\footnotetext{
$\overline{113}$ Ver sobre este último punto, ATIENZA, Manuel, "El derecho como argumentación”, en ATIENZA, Manuel y FERRAJOLI, Luigi, Jurisdicción y argumentación en el Estado constitucional de derecho, México, D.F.: Instituto de Investigaciones Jurídicas, Universidad Nacional Autónoma de México, 2005, p. 72.
} 
fuentes jurídicas que la magistratura constitucional debe manejar en su tarea de interpretación de la Carta Magna y que, en ocasiones, la llevan a "crear" Derecho; y ha crecido en complejidad, alcance y trascendencia la faena de control de constitucionalidad.

2. Específicamente en nuestro país, la innovación constitucional de 1994 ha introducido -al menos desde el plano normative - modificaciones sustanciales al ordenamiento jurídico, entre las que se cuentan en lo que aquí interesa: un postulado de autoafirmación de su fuerza normativa; la ampliación del plafón de derechos explícitos y la resignificación de algunos que constaban en la letra de la Ley Fundamental en la versión anterior a su última modificación; la literalización de los procesos constitucionales de amparo, hábeas corpus y hábeas data; el diseño de un nuevo paradigma del principio de igualdad, caracterizado por la exigencia de complementación de la igualdad formal con la igualdad material o sustancial, por medio de acciones positivas; la adjudicación de cotización constitucional a once instrumentos internacionales en materia de derechos humanos y la atribución congresal post-reforma de tal alcurnia a otros dos documentos en esa área temática; y el acrecimiento del plexo de derechos implícitos por conducto de los que, perteneciendo a tal categoría, provienen de fuente internacional.

3. La mencionada jerarquización constitucional (originaria y derivada) de un conjunto de instrumentos internacionales ha traído consigo la ampliación formal y material del parámetro de control de constitucionalidad, introduciéndose nuevos elementos de ponderación a la labor hermenéutica y aplicativa a cargo de la Corte Suprema. En ese marco, se impone que la tarea interpretativa que desenvuelve se conforme no sólo a la Constitución sino también al derecho internacional de los derechos humanos, labor que exige conocer y aplicar los estándares emergentes de, inter alia, los repertorios de pronunciamientos de la Comisión Interamericana y la jurisprudencia de la Corte Interamericana, en sus precedentes contenciosos y opiniones consultivas.

4. Paralelamente, se añade un nuevo elemento de singular importancia: aquella premisa de hermenéutica conforme al derecho internacional de los derechos humanos ha sido reivindicada también por la propia Corte Interamericana, al poner en cabeza de los poderes judiciales de los Estados la obligación de llevar adelante el 'control de convencionalidad' ("Almonacid Arellano") entre las normas jurídicas internas que aplican en los casos concretos y la $\mathrm{CADH}$, debiendo tenerse en cuenta en tal faena no solamente la literalidad de dicho instrumento internacional sino también -como quedó expuesto- la exégesis que del mismo ha llevado adelante el citado tribunal interamericano en su papel de intérprete último y final. 
Es preciso recordar que tal pauta ha sido recepcionada por la Corte Suprema, plasmándola en "Mazzeo", precedente que aunque despertó polémica ostenta valor institucional.

5. De modo correlativo, se ha intensificado el tenor de exigencia del patrón impuesto fundamentalmente a la Corte Suprema, como órgano de cierre de la jurisdicción constitucional, en la labor de argumentación de sus sentencias, principalmente de aquellas con trascendencia constitucional, como presupuesto de su propia legitimidad institucional. Así, al demandársele un mayor esfuerzo en la justificación racional de sus decisiones, se ve impelida a abandonar atavismos y a recurrir a herramientas interpretativas más sofisticadas, no por esnobismo constitucional sino para reforzar el calibre de las posiciones jurisdiccionales que, en casos complejos, generen precedentes imbuidos de ejemplaridad.

6. Al nombrado cúmulo de factores se le adicionan otras circunstancias: el aludido impacto de la innovación constitucional de 1994 en el ordenamiento jurídico argentino ha acentuado el "proceso de constitucionalización desde el plano normológico", frente al que se ha generado un contrafenómeno: la "desvirtuación o distorsión constitucionales en la dimensión fáctica", patentizado en numerosos aspectos, algunos de los cuales deberán ser definidos por la Corte Suprema; la retracción del Congreso en diversos campos de su incumbencia, el aumento de la ocupación de esos espacios libres por el Poder Ejecutivo y la traslación al Judicial de problemas que en no pocas ocasiones éste no está en condiciones jurídicas ni materiales de resolver; el incesante crecimiento de la demanda de justicia por parte del pueblo, ámbito donde es posible constatar que a mayor desconfianza y subestimación de la magistratura judicial, mayor (en cantidad y calidad) requerimiento de justicia se le dirige.

7. Se verifican también otras circunstancias que a primera vista pueden parecer más "pedestres", aunque ni lo son ni pueden ser soslayadas en un análisis sobre el rol que en la hora actual le toca jugar al Máximo Tribunal: éste, en su nueva composición, intenta despegarse de la "vieja Corte", casi mecánicamente asociable en la percepción popular a la denominada "mayoría automática" que en no escasos fallos avaló la política del ex presidente Menem; la consecuente urgencia de la "nueva Corte" de "relegitimarse" ante la sociedad, dando muestras de independencia y fortaleza para ganar credibilidad; y la sobrecarga de trabajo en el Tribunal, que aloja un gran volumen de causas.

8. Ante un trasfondo y una atmósfera con semejantes ingredientes y condimentos como los hasta aquí relevados, la Corte viene dando muestras en algunas de sus sentencias y acordadas de estar determinada a tonificar su rol institucional "marcando su terreno" como cabeza del Poder Judicial y, a nuestro criterio, a recorrer 
el camino que la lleve a reconvertirse en un tribunal constitucional desde el ángulo material, al mostrarse decidida a concentrar sus esfuerzos y recursos de modo primordial en el tratamiento de cuestiones de real magnitud constitucional.

Varias señales sustentan nuestra percepción preliminar sobre el punto en examen. Así, un seguimiento de algunas sentencias y acuerdos permite constatar: que ha comenzado a recurrir más asiduamente a modalidades sentenciales "atípicas"; a modular temporalmente los efectos del control de constitucionalidad que realiza; a tender lazos dialógicos con otros poderes u órganos de los Estados Nacional o Provinciales; a dar algunos pasos en terrenos inhóspitos del control de constitucionalidad como el de la fiscalización sobre las omisiones inconstitucionales; a examinar cuestiones altri tempi no justiciables; a acudir a nuevas herramientas interpretativas en el marco constitucional; a depurar la competencia discernida por ley del Congreso en el contexto de los recursos ordinarios de apelación en materia previsional, lo que entre otras cosas supone desembarazarse de un buen número de causas; a diseñar un estándar más exigente para habilitar su competencia originaria; a abrir vías de participación popular que puedan llevar a una mayor democratización del debate en cuestiones dilemáticas y de envergadura constitucional (por medio de las figuras del amicus curiae y de las audiencias de carácter público); y a insistir en catalogar como "eminente" el ejercicio de la jurisdicción constitucional a su cargo.

9. Obviamente, ni el cambio será automático ni el camino sencillo. De hecho, más temprano que tarde desde las esferas competentes se deberá definir el emplazamiento de la Corte en el esquema institucional e imaginar vías para solucionar el factor casacional que la inunda. Pronto también, el Tribunal deberá vérselas con cuestiones constitucionales delicadas en sectores cada día más frecuentes de interacción entre el derecho constitucional, el procesal constitucional y el internacional de los derechos humanos; al tiempo que se acumulan los desafíos jurídicos y políticos que tendrá que afrontar para resguardar en la medida de lo posible una "dialéctica institucional correcta"114 con los otros poderes del Estado bajo el manto de la Ley Fundamental, que a todos ellos vincula axiológica y jurídicamente.

10. Lejos de cualquier pretensión de adjudicar valor apodíctico a nuestras reflexiones, en este trabajo sólo hemos pretendido compartir algunas percepciones, eso

$\overline{114}$ La frase entrecomillada corresponde a TARUFFO, Michele, "Jueces y política: de la subordinación a la dialéctica", en Isonomía. Revista de Teoría y Filosofía del Derecho, $\mathrm{N}^{\circ} 22$, abril de 2005, Instituto Tecnológico Autónomo de México, Fontamara, México, D.F., p. 17. El párrafo del que se la ha extraído dice: "el problema de los sistemas democráticos es el de crear, garantizando su funcionamiento, mecanismos de 'checks and balances' capaces de detener la tendencia del poder político a someter a la magistratura y de contener al conflicto fisiológico entre los jueces y el poder dentro de los márgenes de una dialéctica institucional correcta" - énfasis añadido - . 
sí, esperanzadas, en un ámbito neurálgico del accionar de la Corte como órgano de cierre de la jurisdicción constitucional en nuestro país, rol que le exige y demanda el mayor de sus esfuerzos para asumir cabalmente retos sustanciales como los que subyacen en sus funciones de defensora de la Constitución, último reducto protectorio de los derechos humanos en el plano doméstico, colaboradora en la importante tarea de factibilizar la pervivencia de la institucionalidad y legitimidad democráticas al operar como armonizadora de los poderes del Estado y artifice de una convergencia sustentable entre las instancias jurisdiccionales interna e internacional para lograr la efectiva protección del ser humano. 


\section{Referencias Bibliograficas}

ABREGÚ, Martín y COURTIS, Christian, "Perspectivas y posibilidades del amicus curiae en el derecho argentino", en La aplicación de los tratados sobre derechos humanos por los tribunales locales, Centro de Estudios Legales y Sociales, Buenos Aires: Editores del Puerto.

ATIENZA, Manuel, "El derecho como argumentación”, en ATIENZA, Manuel y FERRAJOLI, Luigi, Jurisdicción y argumentación en el Estado constitucional de derecho, México, D.F.: Instituto de Investigaciones Jurídicas, Universidad Nacional Autónoma de México, 2005.

BARROSO, Luís Roberto, "O começo da história. A nova interpretação constitucional e o papel dos princípios no direito brasileiro", en AA.VV., Visión iberoamericana del tema constitucional, Caracas: Fundación Manuel García-Pelayo, 2003.

BAZÁN, Víctor, "Neoconstitucionalismo e inconstitucionalidad por omisión", La Ley, T²005-F, Buenos Aires, pp. 775/793.

BAZÁN, Víctor. "El amicus curiae en clave de derecho comparado y su reciente impulso en el derecho argentino", Cuestiones constitucionales. Revista Mexicana de Derecho Constitucional, $\mathrm{N}^{\circ} 12$, enero-junio 2005, México, D.F.: Instituto de Investigaciones Jurídicas, Universidad Nacional Autónoma de México.

BAZÁN, Víctor, "La Corte Suprema de Justicia argentina y la depuración de su competencia apelada por medio del control de constitucionalidad”, Revista Iberoamericana de Derecho Procesal Constitucional, N 5, enero/ junio 2006, Instituto Iberoamericano de Derecho Procesal Constitucional, México, D.F.: Edit. Porrúa.

BAZÁN, Víctor. "El amicus curiae y su debut en la jurisprudencia de la Sala Primera de la Suprema Corte de Justicia de Mendoza”, La Ley Gran Cuyo, Año 11, № 6, Mendoza, julio 2006.

BAZÁN, Víctor, "Algunos problemas y desafíos actuales de la jurisdicción constitucional en Iberoamérica”, Anuario de Derecho Constitucional Latinoamericano 2007, T I, Montevideo: Fundación Konrad Adenauer, 2007.

BAZÁN, Víctor, ver "Respuestas normativas y jurisdiccionales frente a las omisiones inconstitucionales: una visión de derecho comparado", en CARBONELL, Miguel (coordinador), En busca de las normas ausentes. Ensayos sobre la inconstitucionalidad por omisión, $2^{a}$ ed., México, D.F.: Instituto de Investigaciones Jurídicas, Universidad Nacional Autónoma de México, 2007.

BAZÁN, Víctor, "De jueces subrogantes, casos difíciles y sentencias atípicas", Jurisprudencia Argentina, Buenos Aires: LexisNexis, 15 de agosto de 2007.

BAZÁN, Víctor, "Derecho Procesal Constitucional: estado de avance, retos y prospectiva de la disciplina", La Ley. Suplemento de Derecho Constitucional, Buenos Aires, 27 de agosto de 2007.

BAZÁN, Víctor. "El derecho internacional de los derechos humanos y el derecho interno en el escenario argentino: convergencias y desencuentros", El Derecho. Serie Especial "Constitucional”, Buenos Aires, 16 de noviembre de 2007.

BAZÁN, Víctor. "La interacción del derecho internacional de los derechos humanos y el derecho interno en Argentina”, Estudios Constitucionales. Revista semestral del Centro de Estudios Constitucionales, Santiago de Chile: Universidad de Talca, en prensa.

BOLÍVAR, Ligia, "Justicia y acceso. Los problemas y las soluciones”, Revista del Instituto Interamericano de Derechos Humanos, Nos. 32-33, Edición especial sobre 'Acceso a la Justicia', per. julio 2001-junio 2002, Instituto Interamericano de Derechos Humanos, San José de Costa Rica.

CARBONELL, Miguel. Neoconstitucionalismo(s), Madrid: Trotta - Universidad Nacional Autónoma de México, 2003.

CÁRDENAS GRACIA, Jaime, “Los principios y su impacto en la interpretación constitucional y judicial”, en FERRER MAC-GREGOR, Eduardo (coordinador), Interpretación constitucional, T I, México, D.F.: Edit. Porrúa y Universidad Nacional Autónoma de México (Instituto de Investigaciones Jurídicas), 2005.

CARRILLO, Marc, "La Jurisdicción Constitucional en Europa: las funciones del Tribunal Constitucional Español y las hipotecas del caso chileno”, en MORODO, Raúl y DE VEGA, Pedro (directores), Estudios de Teoría del Estado y Derecho Constitucional en honor de Pablo Lucas Verdú, T II, Madrid: Universidad Nacional Autónoma de México (Instituto de Investigaciones Jurídicas) y Servicio de Publicaciones de la Facultad de Derecho de la Universidad Complutense de Madrid, 2000.

Corte Interamericana de Derechos Humanos. Serie A, San José de Costa Rica.

Corte Interamericana de Derechos Humanos. Serie C, San José de Costa Rica. 
DÍAZ REVORIO, Francisco J., "El control de constitucionalidad de las omisiones legislativas relativas en el derecho comparado europeo", Revista Española de Derecho Constitucional, N 61, Año 21, enero-abril 2001, Madrid: Centro de Estudios Políticos y Constitucionales.

FIORAVANTI, M., Constitución. De la antigüedad a nuestros días [1999], trad. de M. Martínez Neira, Madrid: Trotta, 2001.

GARRORENA MORALES, Ángel, "Opacidad y desestimación de la inconstitucionalidad en el fallo de las sentencias interpretativas”, La Democracia Constitucional. Estudios en homenaje al Profesor Francisco Rubio Llorente, Congreso de los Diputados, Tribunal Constitucional, Madrid: Universidad Complutense de Madrid, Fundación Ortega y Gasset, Centro de Estudios Políticos y Constitucionales, 2002.

GASCÓN ABELLÁN, Marina, Voz: "Interpretación conforme (con la Constitución)", en Diccionario de Derecho Constitucional, México, D.F.: Edit. Porrúa y Universidad Nacional Autónoma de México (Instituto de Investigaciones Jurídicas), 2002.

GONZÁLEZ BEILFUSS, Markus, Tribunal Constitucional y reparación de la discriminación normativa, Madrid: Centro de Estudios Políticos y Constitucionales, 2000.

GROPPI, Tania, “¿Hacia una justicia constitucional 'dúctil’? Tendencias recientes de las relaciones entre Corte Constitucional y jueces comunes en la experiencia italiana”, en FERRER MAC-GREGOR, Eduardo (coordinador), Derecho Procesal Constitucional, $T^{\circ}$ I, $4^{a}$ ed., Colegio de Secretarios de la Suprema Corte de Justicia de la Nación, A.C., México, D.F.: Edit. Porrúa, 2003.

GUASTINI, Riccardo, “La ‘constitucionalización’ del ordenamiento jurídico: el caso italiano”, trad. de José María Lujambio, Estudios de teoría constitucional, $1^{a}$ reimpr., Doctrina Jurídica Contemporánea, Fontamara, México, D.F., 2003, p. 153.

LÓPEZ BOFILL, Héctor, Decisiones interpretativas en el control de constitucionalidad de la ley, Valencia: Instituto Vasco de Administración Pública, Tirant lo Blanch, 2004.

MINISTERIO DE RELACIONES EXTERIORES. "Derechos Humanos: La Argentina se convirtió hoy en el primer país de América en ratificar la Convención contra las Desapariciones Forzadas", Información para la Prensa $N^{\circ}$ 519/07, 14 de diciembre de 2007, Fuente: www.cancilleria.gov.ar/portal/prensa.

MORELLO, Augusto M., La Corte Suprema en el sistema político, Buenos Aires: Librería Editora Platense y LexisNexis, 2005.

NOGUEIRA ALCALÁ, Humberto, Lineamientos de interpretación constitucional y del bloque constitucional de derechos, Santiago de Chile: Librotecnia, 2006.

PINTO, Mónica, "El principio pro homine. Criterios de hermenéutica y pautas para la regulación de los derechos humanos", en ABREGÚ, Martín y COURTIS, Christian (compiladores), La aplicación de los tratados sobre derechos humanos por los tribunales locales, Centro de Estudios Legales y Sociales, Buenos Aires: Editores del Puerto.

PRIETO SANCHÍS, Luis, voz “Neoconstitucionalismo”, en CARBONELL, Miguel (coordinador), Diccionario de derecho constitucional, México, D.F.: Edit. Porrúa y Universidad Nacional Autónoma de México (Instituto de Investigaciones Jurídicas), 2002.

RUBIO LLORENTE, Francisco, en el capítulo "La jurisdicción constitucional como forma de creación del derecho" de su libro La forma del poder. Estudios sobre la Constitución, $2^{a}$ ed., Madrid: Centro de Estudios Constitucionales, 1997.

SASTRE ARIZA, Santiago, "La ciencia jurídica ante el neoconstitucionalismo", en CARBONELL, Miguel. Neoconstitucionalismo(s), Madrid: Trotta - Universidad Nacional Autónoma de México, 2003.

TAJADURA TEJADA, Javier, "Retos y desafíos de la justicia constitucional en los umbrales del siglo XXI", en AA.VV., Visión iberoamericana del tema constitucional, Caracas: Fundación Manuel García-Pelayo, 2003.

TORRES DEL MORAL, Antonio, "El instituto de la rigidez como garantía de la Constitución”, en BAZÁN, Víctor [coordinador], Defensa de la Constitución. Garantismo y controles. Libro en reconocimiento al Doctor Germán J. Bidart Campos, Buenos Aires: Ediar, 2003.

VILLAVERDE MENÉNDEZ, Ignacio, La inconstitucionalidad por omisión, Madrid: McGraw-Hill, 1997.

WESSEL, W., "Die Rechtsprechung des Bundesverfassungsgerichts zur Verfassungsbeschwerde”, Deutsches Verwaltungsblatt (DVBl), cuad. 6, 1952.

ZAGREBELSKY, Gustavo, El derecho dúctil. Ley, derechos, justicia, trad. de Marina Gascón, 3. ed. Madrid: Trotta, 1999. 